\title{
NF-אB DECOY OLIGODEOXYNUCLEOTIDE PRESERVES DISC HEIGHT IN A RABBIT ANULAR-PUNCTURE MODEL AND REDUCES PAIN INDUCTION IN A RAT XENOGRAFT-RADICULOPATHY MODEL
}

\author{
K. Kato ${ }^{1,2,}$, K. Akeda ${ }^{3,4}$, , S. Miyazaki ${ }^{2,5}$, J. Yamada ${ }^{2,3}$, C. Muehleman ${ }^{4}$, K. Miyamoto ${ }^{4,6}$, Y.A. Asanuma ${ }^{4,7}$, \\ K. Asanuma ${ }^{4,3}$, T. Fujiwara ${ }^{2,3}$, M.E. Lenz ${ }^{2}$, T. Nakazawa ${ }^{8}$, H. An ${ }^{4}$ and K. Masuda ${ }^{1, *}$ \\ ${ }^{1}$ Department of Orthopedic Surgery, Nagoya City University, 1 Kawasumi, Mizuho-cho, Mizuho-ku, \\ Nagoya 467-8601, Japan \\ ${ }^{2}$ Department of Orthopedic Surgery, University of California, San Diego, 9500 Gilman Drive, La Jolla, \\ CA 92093, USA \\ ${ }^{3}$ Department of Orthopedic Surgery, Mie University, 2-174 Edobashi, Tsu, Mie 514-8507, Japan \\ ${ }^{4}$ Department of Orthopedic Surgery, Rush University Medical Center, 1611 West Harrison St. Suite 300, \\ Chicago, IL 60612, USA \\ ${ }^{5}$ Department of Orthopedic Surgery, Kobe University, 7-5-1 Kusunokimachi, Chuo-ku, Kobe, \\ Hyogo 650-0017, Japan \\ ${ }^{6}$ Spine Center, Gifu Municipal Hospital, 7-1 Kashima-cho, Gifu, Gifu 500-8513, Japan \\ ${ }^{7}$ Department of Orthopedic Surgery, Murase hospital, 3-12-10 Kanbe, Suzuka, Mie 513-0801, Japan \\ ${ }^{8}$ AnGes, Inc. 4-13-3, Shiba, Minato-ku, Tokyo 108-0014, Japan \\ $\S$ These authors contributed equally to this work
}

\begin{abstract}
While it is known that the degenerated intervertebral disc (IVD) is one of the primary reasons for low-back pain and subsequent need for medical care, there are currently no established effective methods for direct treatment. Nuclear factor $-\kappa \mathrm{B}(\mathrm{NF}-\kappa \mathrm{B})$ is a transcription factor that regulates various genes' expression, among which are inflammatory cytokines, in many tissues including the IVD. NF- $\kappa$ B decoy is an oligodeoxynucleotide containing the NF- $\kappa \mathrm{B}$ binding site that entraps NF- $\kappa \mathrm{B}$ subunits, resulting in suppression of NF- $\kappa \mathrm{B}$ activity. In the present preclinical study, NF- $\kappa \mathrm{B}$ decoy was injected into degenerated IVDs using the rabbit anularpuncture model. In terms of distribution, NF- $\kappa B$ decoy persisted in the IVDs up to at least 4 weeks after injection. The remaining amount of NF- $\kappa B$ decoy indicated that it fit a double-exponential-decay equation. Investigation of puncture-caused degeneration of IVDs showed that NF- $\kappa$ B decoy injection recovered, dosedependently, the reduced disc height that was associated with reparative cell cloning and morphological changes, as assessed through histology. Gene expression, by quantitative real-time polymerase chain reaction (qRT-PCR), showed that NF- $\kappa$ B decoy attenuated inflammatory gene expression, such as that of interleukin-1 and tumor necrosis factor- $\alpha$, in rabbit degenerated IVDs. NF- $\kappa$ B decoy also reduced the pain response as seen using the "pain sensor" nude rat xenograft-radiculopathy model. This is the first report demonstrating that NF- $\kappa$ B decoy suppresses the inflammatory response in degenerated IVDs and restores IVD disc height loss. Therefore, the intradiscal injection of NF- $\kappa$ B decoy may have the potential as an effective therapeutic strategy for discogenic pain associated with degenerated IVDs.
\end{abstract}

Keywords: Intervertebral disc-repair/regeneration, intervertebral disc-degeneration, animal models-general, nuclear factor $-\kappa \mathrm{B}$, decoy, intervertebral disc-histology, intradiscal injection, translational and preclinical research.

*Address for correspondence: Koichi Masuda, Department of Orthopedic Surgery, University of California, San Diego, 9500 Gilman Drive, La Jolla, CA 92093, USA.

Telephone number: +1 8582460426 Email: komasuda@ucsd.edu

Copyright policy: This article is distributed in accordance with Creative Commons Attribution Licence (http://creativecommons.org/licenses/by-sa/4.0/).

\begin{tabular}{llll}
\hline & List of Abbreviations & ANOVA & analysis of variance \\
& & COL2A1 & collagen type II alpha 1 chain \\
AF & annulus fibrosus & DHI & disc height index \\
ACAN & aggrecan & DRG & dorsal root ganglion
\end{tabular}




\begin{tabular}{|c|c|}
\hline FAM & fluorescein amidite \\
\hline GDF6 & growth differentiation factor 6 \\
\hline IL & interleukin \\
\hline IVD & intervertebral disc \\
\hline LC/MS/MS & $\begin{array}{l}\text { liquid chromatography/tandem- } \\
\text { mass spectrometry }\end{array}$ \\
\hline LSD & least significant difference \\
\hline MMP & matrix metalloproteinase \\
\hline MRI & magnetic resonance imaging \\
\hline$N F-\kappa B$ & nuclear factor- $\kappa \mathrm{B}$ \\
\hline NGF & nerve growth factor \\
\hline NP & nucleus pulposus \\
\hline PBS & phosphate-buffered saline \\
\hline PTGS2 & $\begin{array}{l}\text { prostaglandin-endoperoxide } \\
\text { synthase } 2\end{array}$ \\
\hline qRT-PCR & $\begin{array}{l}\text { quantitative real-time polymerase } \\
\text { chain reaction }\end{array}$ \\
\hline TNF & tumor necrosis factor \\
\hline VEGF & vascular endothelial growth factor \\
\hline
\end{tabular}

\section{Introduction}

Low-back pain is one of the most frequent medical symptoms causing physical limitation and even sick leave for the working population of many countries (Garcia et al., 2014; Meucci et al., 2015; Raciborski et al., 2016). A worldwide analysis has reported that low-back pain is the leading cause of years lived with disability (Murray et al., 2018). There are various risk factors for low-back pain, including obesity, smoking, age, and economic status. The degenerated IVD is one of the main reasons for low-back pain and, thus, there have been many efforts to evaluate the correlation between low-back pain and degenerated IVDs (Ito and Creemers, 2013; Samartzis et al., 2015). To date, if the goal is only to reduce pain, then physical therapy, medication, and surgical treatments, such as fixation, are considered. However, there are currently no established effective methods to treat the degenerated IVD.

The inflammatory response plays an important role in IVD degeneration (Fontana et al., 2015; Molinos et al., 2015). Inflammatory cytokines, such as ILs and TNF- $\alpha$, have been observed in degenerated IVDs. These cytokines enhance aggrecanases, resulting in aggrecan degradation. IL- $1 \beta$ stimulates VEGF expression and promotes neovascularization, thus allowing the infiltration of macrophages, which trigger inflammation. NF- $\kappa \mathrm{B}$ is a transcription factor that regulates gene expression, including that of inflammatory cytokines, in many cell types (Ling and Kumar, 2012; Mantamadiotis, 2017; Manthiram et al., 2017). NF- $\kappa$ B is also reported to be involved in IVD degeneration (Huang et al., 2017; Wang et al., 2017). For example, TNF- $\alpha$ is reported to require the NF- $\kappa B$ pathway in NP cells to mediate IVD degeneration and the expression of the matrix catabolism-controlling MMP-3 or MMP-13 (Liacini et al., 2003; Liu et al., 2017; Wang et al., 2014). Peroxisome proliferator-activated receptor $\gamma$, which is associated with osteoarthritis and rheumatoid arthritis, is also reported to be involved in the IL-17-mediated NF- $\kappa$ B pathway in inflammation and degeneration of IVDs (Liu et al., 2019). NF- $\kappa$ B activation by IL-1 $\beta$ increases gene and protein expression of MMPs in NP cells (Zhongyi et al., 2015).

$\mathrm{NF}-\kappa \mathrm{B}$ is first activated by pro-inflammatory cytokines, including IL-1 $\beta$ and TNF- $\alpha$, and then translocates into the cell nucleus where it binds to the enhancer elements of genes to increase pro-inflammatory transcripts. NF- $\kappa \mathrm{B}$ decoy is an oligodeoxynucleotide containing NF- $\kappa \mathrm{B}$ binding site (GGGATTTCCC) that entrap NF- $\kappa$ B subunits (De Stefano, 2011; Morishita et al., 1997). Thus, activated NF- $\kappa$ B would bind to NF- $\kappa$ B decoy instead of DNA enhancer elements, resulting in inhibition of NF- $\kappa \mathrm{B}$-activated gene expression (Fig. 1). NF- $\kappa \mathrm{B}$ decoy is already known as a promising drug in some inflammatory diseases, such as atopic dermatitis, respiratory disease, and cardiovascular disease (Matsuda et al., 2005; Morishita et al., 1997; Nakamura et al., 2002). Therefore, because IVD degeneration is related to inflammatory changes, the study hypothesis was that NF- $\kappa \mathrm{B}$ decoy would improve the homeostasis of the degenerated IVD and, thus, be a promising candidate for IVD disease treatment.

When the structure of the IVD and its blood supply from the systemic circulation are considered, the local administration of therapeutic molecules to degenerated IVDs has significant advantages. Local administration as an intradiscal injection can achieve a high concentration of molecules in the IVD as a minimally invasive approach without the necessity of delivering large amounts of a molecule. Intradiscal injection of various drugs or biologics have been reported to have promising effects on treating lowback pain (Chujo et al., 2006; Masuda et al., 2006; Mwale et al., 2003; Obata et al., 2012). Recently, an intradiscal injection of cytokine inhibitors has been reported to treat patients suffering from back pain (Sainoh et al., 2016a; 2016b). In addition, several drugs and biologics are at the clinical trial stage (Akeda et al., 2017; Nguyen et al., 2017; Peng et al., 2010). However, the exact mechanism of elimination and distribution of injected molecules is not well known.

Importantly, because of the unique environment of the IVD, such as its hypoxic condition, low cell density, and limited diffusion, careful consideration should be given when introducing a new reagent to clinical therapy or even to apply reagents that are already clinically used to treat a disease: the safety and mode of action should be thoroughly investigated prior to the use of any reagent in the clinic. To examine the efficacy of a treatment for degenerated IVD diseases, such as relieving pain, inhibiting degeneration, or even reversing degeneration, appropriate preclinical animal models should be used. It is also not yet clear how often reagent injection should be performed; in other words, it must be understood how long injected reagents stay within the injected IVD. Therefore, to 
develop therapeutic drugs with appropriate injection dosage and frequency, in addition to the efficacy study, the investigation of distribution and half-life of injected agents in the IVD is essential.

The rabbit anular-puncture model is an established method to investigate IVD degeneration (Masuda et al., 2005) and has been used to evaluate new reagents in the treatment of disc degeneration as a preclinical animal model (Chujo et al., 2006; Masuda et al., 2006). While there are several choices to evaluate pain in animal models, the von Frey test is commonly used for rodents in nerve injury models, osteoarthritis, and discogenic pain (Fukui et al., 2018; Khasabov et al., 2017; Philpott et al., 2017; Srebro et al., 2016). To demonstrate that degenerated IVDs could indeed produce pain, Kawakami et al. (2000) first reported a rat radiculopathy model with transplantation of degenerated discs. The present study, using the rabbit anular-puncture model and the rat xenograft-radiculopathy model (Miyazaki et al., 2018), showed that injected NF- $\kappa$ B decoy attenuated the inflammatory response in degenerated IVDs, restored disc height, and reduced the pain response in rats.

\section{Materials and Methods}

\section{NF- $\kappa$ B decoy}

$\mathrm{NF}-\kappa \mathrm{B}$ decoy is an oligodeoxynucleotide containing NF- $\kappa \mathrm{B}$ binding site (GGGATTTCCC) (Fig. 1b). The sequence of phosphorothioate doublestranded decoy against NF- $\kappa$ B binding site have been previously reported (consensus sequence 5'-CCTTGAAGGGATTTCCCTCC-3') (Morishita et al., 1997). In the present study, several forms of NF$\kappa B$ decoy were prepared. FAM-labeled NF- $\kappa$ B decoy (FAM decoy) and radiolabeled NF- $\kappa$ B decoy ( ${ }^{3} \mathrm{H}-\mathrm{NF}-$ $\kappa B$ decoy) were used in the distribution study. The specific activity of ${ }^{3} \mathrm{H}-\mathrm{NF}-\kappa \mathrm{B}$ decoy was $1190 \mu \mathrm{Ci} /$ $\mathrm{mg}$ and it was administered at a mean dose level of $470 \mu \mathrm{Ci} /$ animal. All types of NF- $\kappa \mathrm{B}$ decoy were provided by AnGes, Inc. (Tokyo, Japan).

\section{Rabbit anular-puncture disc degeneration model and injection of NF- $\kappa$ B decoy}

All surgical procedures were performed with the approval of the Institutional Animal Care and Use Committee at University of California San Diego, Rush University and Covance Inc. New Zealand white rabbits, weighing approximately $3.5-4.0 \mathrm{~kg}$ (5-6 months-old), were used. A scheme of animal experiments is presented in Fig. 2. Two series of animal studies for evaluating radiographic disc height were performed to determine the duration of NF- $\kappa$ B decoy (Fig. 2a, experiment 1) and the dose-effect after the injection (Fig. 2b, experiment 2 ). Anular puncture and decoy injection were performed as previously described (Masuda et al., 2005; 2006). Under general anesthesia, the rabbits were placed into a lateral prone position, and a posterolateral retroperitoneal approach was used to expose the anterior surfaces of lumbar IVDs. After palpation to determine the disc levels, the areas to be punctured (1-2 $\mathrm{mm}$ diameter) or injected were carefully exposed with retraction of the nerve lying on the surface of the IVD (especially at the L $4 / 5$ level). To confirm the IVD level, a titanium clip was placed, and radiographs were taken before anular puncture or injection. After puncture or injection, layered sutures were administered, and rabbits were recovered. To induce disc degeneration, the initial puncture with an 18-Gauge needle at a $5 \mathrm{~mm}$ depth of puncture was performed on two noncontiguous discs (L2/3 and L4/5), with the disc (L3/4) between the punctured discs left intact as a control. 4 weeks after the initial puncture, the discs were exposed again from the contralateral side, and either the vehicle (PBS; $10 \mu \mathrm{L}$ per disc) or the NF-kB decoy $(0.1,1,10$, 30 , or $100 \mu \mathrm{g}$ in $10 \mu \mathrm{L}$ PBS per disc) was injected into the center of the NP using a tapered 26-Gauge needle (XX*MS16, Ito Corporation, Shizuoka, Japan). Rabbits were euthanized at 8,16 , or 28 weeks after the initial anular puncture $(4,12$, or 24 weeks after the injection, respectively). In experiment 1 , all rabbits with anular puncture were included and randomly assigned to experimental groups. In experiment 2 , radiographs at the 2-week time point were used to exclude discs that did not respond to puncture. The exclusion criteria for all outcome measures were that the DHI of the punctured disc remained higher than $90 \%$ of that of non-punctured internal control disc. Then, rabbits were randomly assigned to experimental groups.

\section{Distribution studies}

Under general anesthesia, naïve rabbits received a single injection of FAM decoy (30 $\mu \mathrm{g}$ in $10 \mu \mathrm{L}$ PBS per disc) into L2/3, L3/4, L4/5 and L5/6 IVDs (10 rabbits), ${ }^{3} \mathrm{H}-\mathrm{NF}-\kappa \mathrm{B}$ decoy into L3/4 IVDs (10 rabbits) or native NF- $\kappa \mathrm{B}$ decoy into L3/4 IVDs (30 rabbits). Naïve animals were injected without inducing disc degeneration. Injected IVDs were collected at various time points for up to 4 weeks. The distribution of FAM decoy was visualized by confocal microscopy (Leica SP5); the remaining amount of injected agents in IVDs was quantified following papain digestion. For the measurement of ${ }^{3} \mathrm{H}-\mathrm{NF}-\kappa \mathrm{B}$ decoy and native NF- $\kappa \mathrm{B}$ decoy, the amount of NF- $\kappa$ B decoy was quantified using whole-body autoradiography and a liquid scintillation counter, and LC/MS/MS, respectively.

\section{Fluorescence analysis of FAM decoy}

IVDs were dissected at indicated time points after FAM decoy injection. L4/5 and L5/6 IVDs were dissected as a block and immediately visualized by confocal microscopy on the day of euthanasia. The images were processed using the Leica Application Suite. After dissection, NP and AF of L2/3 and L3/4 IVDs were separated and frozen at $-80^{\circ} \mathrm{C}$ for future quantification. Once all samples were collected for quantification, they were digested individually in $1 \mathrm{~mol} / \mathrm{L} \mathrm{KOH}(0.5 \mathrm{~mL}$ for NP and $1 \mathrm{~mL}$ for $\mathrm{AF})$ at 
$56{ }^{\circ} \mathrm{C}$ overnight according to the previous report by Nemeth et al. (2015), with some modifications (digestion only overnight instead of 1 week). This procedure completely solubilized the tissues and the $\mathrm{KOH}$ was then neutralized using glacial acetic acid. The fluorescence in each sample was measured to determine the amount of remaining FAM decoy in IVDs using a plate reader (BioTek).

\section{Whole-body autography}

Following euthanasia, whole rabbit bodies injected with ${ }^{3} \mathrm{H}-\mathrm{NF}-\kappa \mathrm{B}$ decoy were immediately prepared for cryo-sectioning to visualize the mid-sagittal plane. Sections were exposed to imaging plates (Fujifilm), plates were scanned, and radioactivity of ${ }^{3} \mathrm{H}-\mathrm{NF}-\kappa \mathrm{B}$ decoy was quantified. Standard curve calibrators were embedded in the same blocks of the animals to construct a calibration curve to quantify concentration. Two distinct half-lives were calculated using the double-exponential-decay formula with the amount of ${ }^{3} \mathrm{H}-\mathrm{NF}-\kappa \mathrm{B}$ decoy remaining (SigmaPlot, Systat Software Inc., San Jose, CA, USA) (Mok et al., 1994). The equation was formulated as follows:

$$
f(x)=a e^{-b x}+c e^{-d x}
$$

This explains the two-compartment model of

a

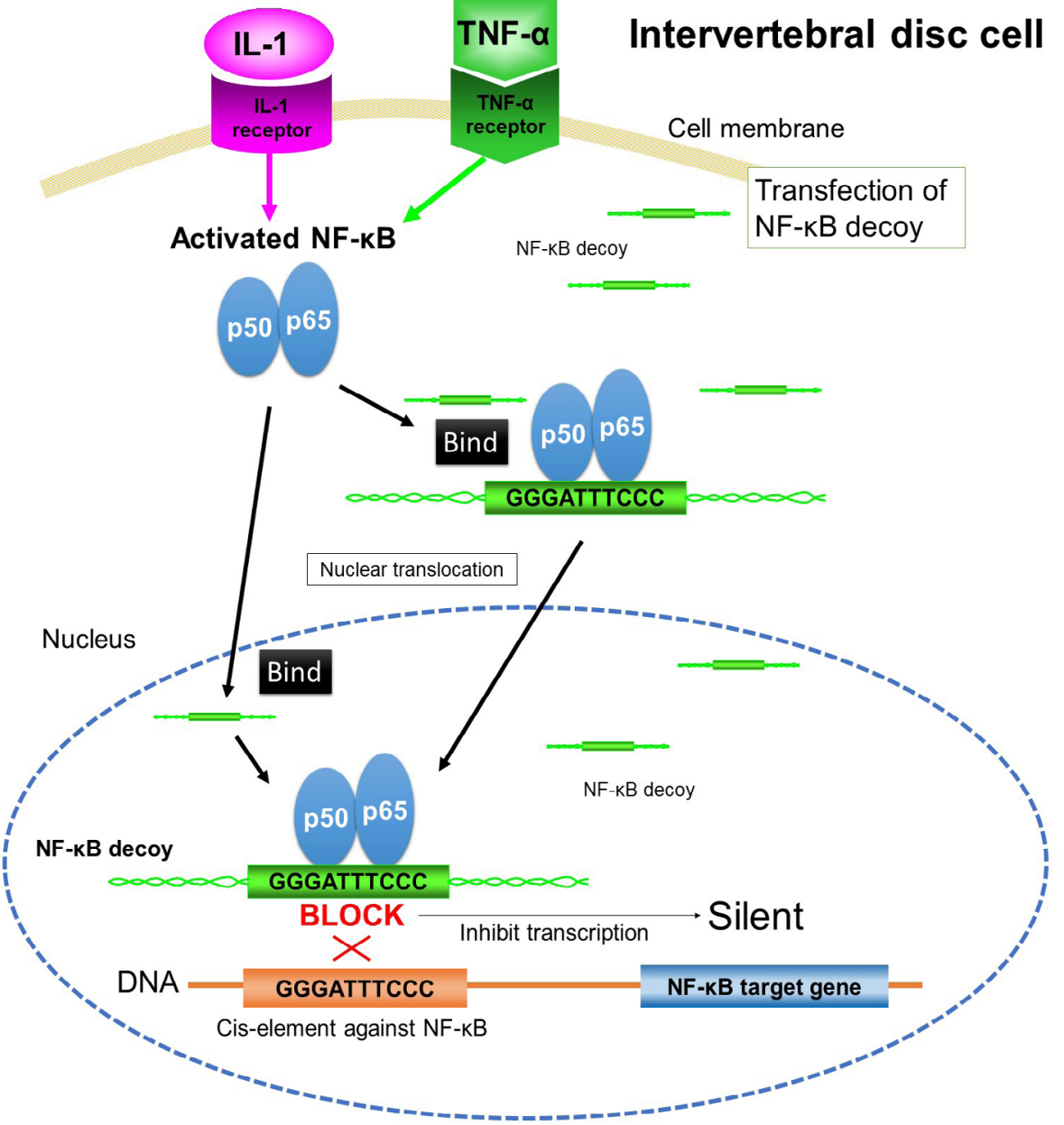

b

\section{NF-kB binding site CCTTGAAGGGATTTCCCTCC GGAACTTCCCTAAAGGGAGG}

Double strands bound by hydrogen bonds

Phosphorotioate nucleic acid analogs to protect nuclease degradation

Fig. 1. Schematic of NF-кB decoy effect. (a) NF- $\kappa B$ is first activated by pro-inflammatory cytokines and then translocates into the cell nucleus where it binds to the enhancer elements of genes to increase pro-inflammatory transcripts. NF- $\kappa B$ decoy is an oligodeoxynucleotide containing NF- $\kappa B$ binding site (GGGATTTCCC), which entraps NF- $\kappa$ B subunits. Thus, activated NF- $\kappa B$ would bind to NF- $\kappa B$ decoy instead of DNA enhancer elements, resulting in inhibition of NF-kB-activating gene expression. (b) The structure of NF-kB decoy. 
pharmacokinetics (a, b, c, d: constants characterizing a multi-exponential decay; a: distribution phase original amount; b: distribution declining rate; c: elimination phase original amount; d: elimination declining rate; $x$ : time (hour). According to this equation, the distribution half-life was calculated by

$$
\frac{\ln 2}{b}
$$

and elimination half-life was defined by

$$
\frac{\ln 2}{d}
$$

\section{LC/MS/MS analysis}

LC/MS/MS analysis was performed to quantify the amount of native NF- $\kappa$ B decoy. Control and standard samples were generated from normal rabbit IVDs that were obtained from carcasses of animals utilized for other studies by adding a known amount of NF- $\kappa$ B decoy. Dissected IVDs were digested by $10 \times$ wet weight of $\mathrm{KOH}$ at $56{ }^{\circ} \mathrm{C}$ overnight. $\mathrm{KOH}$ was neutralized by glacial acetic acid. The IVD-KOH solution containing NF- $\kappa$ B decoy was analyzed by a $\mathrm{LC} / \mathrm{MS} / \mathrm{MS}$ system and the amount of NF- $\kappa \mathrm{B}$ decoy was determined.

\section{Radiographic analysis of disc height}

Radiographs were taken at 2-week intervals up to 16 weeks and, subsequently, at 4-week intervals up to 28 weeks after the initial puncture. Extreme care was taken to maintain a consistent level of anesthesia during radiography of each animal at each time point to obtain a similar degree of muscle relaxation, which may affect the disc height. The pre-operative radiograph was always used as a

a Experiment 1. Long-term study

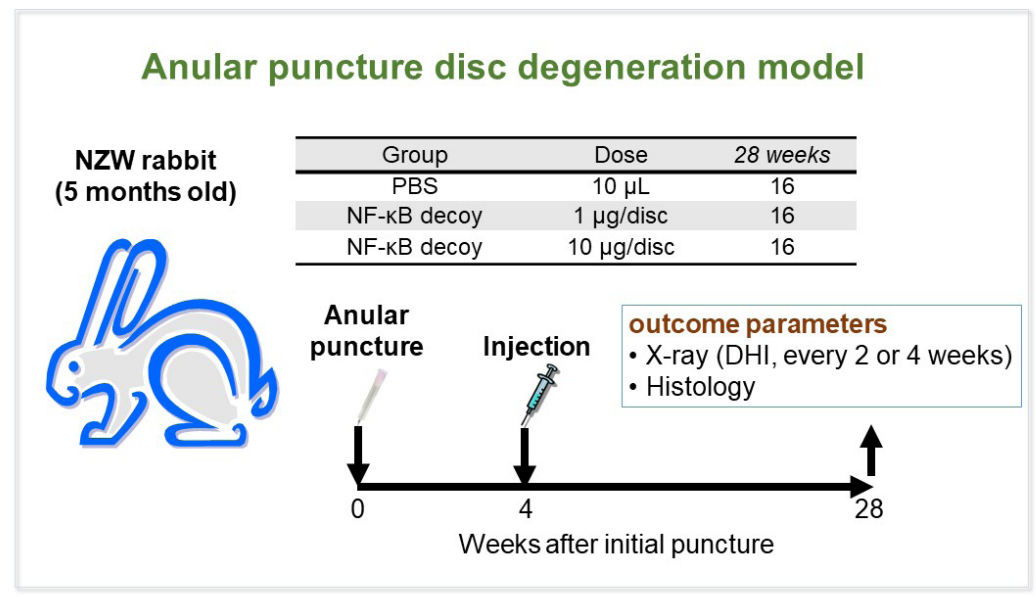

b Experiment 2. Dose-finding study

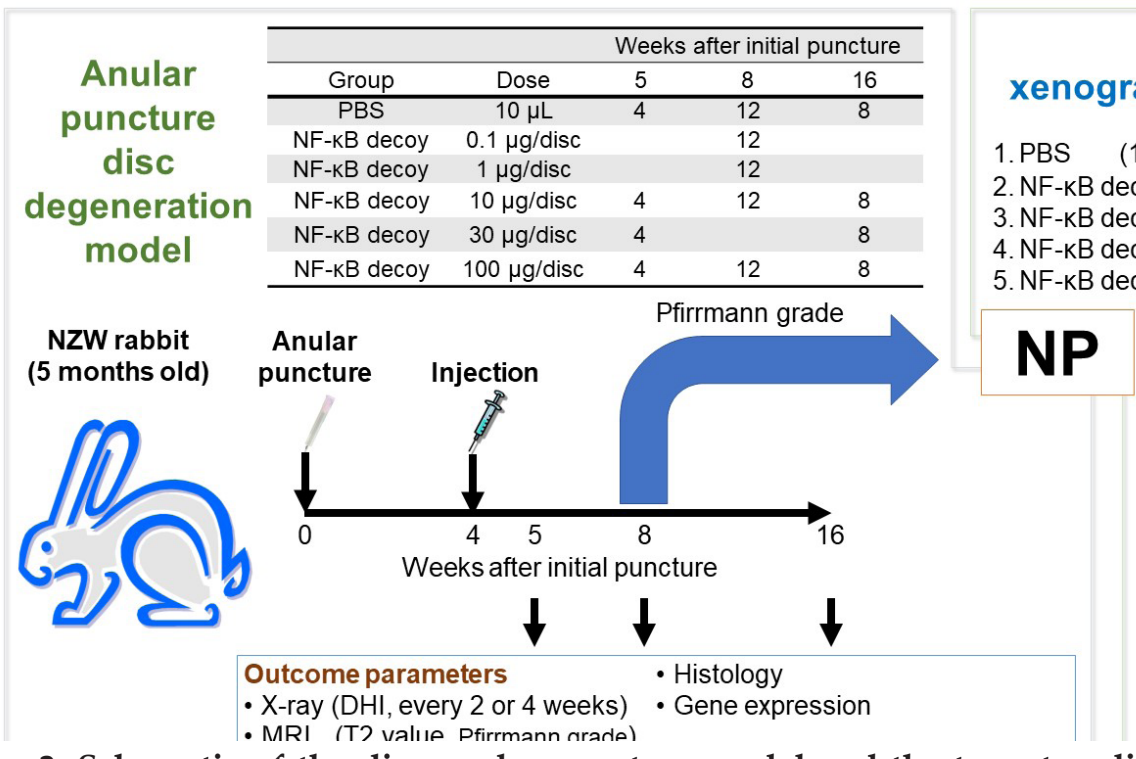

Nude rat disc

ft-radiculopathy model

PBS $\quad(10 \mu \mathrm{L} / \mathrm{disc})$

NF-KB decoy $(0.1 \mu \mathrm{g} / \mathrm{disc})$

NF-kB decoy $(1 \mu \mathrm{g} / \mathrm{disc})$

NF-kB decoy $(10 \mu \mathrm{g} / \mathrm{disc})$

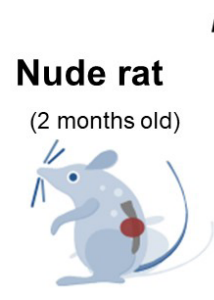

$n=8 /$ group

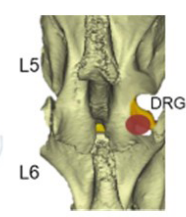

Outcome parameters - von Frey test

Fig. 2. Schematic of the disc anular-puncture model and the two-step disc xenograft radiculopathy model using rabbits and nude rats. (a) Experiment 1 . Long term study. Rabbits received the disc anular puncture followed by intradiscal injection of NF- $\kappa \mathrm{B}(10 \mu \mathrm{g} / \mathrm{disc})$ or PBS. X-ray (DHI) and histology were assessed 24 weeks after injection. (b) Experiment 2. Dose study. Rabbits received anular puncture followed by intradiscal injection of NF- $\kappa B(0.1,1,10,30$ or $100 \mu \mathrm{g} /$ disc $)$ or PBS. X-ray (DHI), MRI (T2 value), histology and gene expression were assessed 1, 4 or 12 weeks after injection. The NP tissue of rabbits 4 weeks after injection were transplanted on nude rat discs. The von Frey test was assessed for pain outcome. 
Table 1. Definition of histological grading scale. Histological grading scale based on 4 categories of degenerative changes, with scores ranging from a normal disc with 4 points ( 1 point in each category) to a severely degenerated disc with 12 points ( 3 points in each category).

\begin{tabular}{|c|c|c|}
\hline Features & Grade & Description \\
\hline \multirow[t]{3}{*}{ I. AF } & 1 & $\begin{array}{l}\text { Normal, pattern of fibrocartilage lamellae (U-shaped in the posterior } \\
\text { aspect and slightly convex in the anterior aspect) without ruptured } \\
\text { fibers and without a serpentine appearance anywhere within the AF }\end{array}$ \\
\hline & 2 & Ruptured or serpentine patterned fibers in less than $30 \%$ of the AF \\
\hline & 3 & Ruptured or serpentine patterned fibers in more than $30 \%$ of the $\mathrm{AF}$ \\
\hline \multirow{3}{*}{$\begin{array}{l}\text { II. Border between } \\
\text { the AF and NP }\end{array}$} & 1 & Normal \\
\hline & 2 & Minimally interrupted \\
\hline & 3 & Moderate/severe interruption \\
\hline \multirow{3}{*}{$\begin{array}{l}\text { III. Cellularity of } \\
\text { the NP }\end{array}$} & 1 & $\begin{array}{c}\text { Normal cellularity with large vacuoles in the gelatinous structure } \\
\text { of the matrix }\end{array}$ \\
\hline & 2 & Slight decrease in the number of cells and fewer vacuoles \\
\hline & 3 & $\begin{array}{c}\text { Moderate/severe decrease (50\%) in the number of cells and no } \\
\text { vacuoles }\end{array}$ \\
\hline \multirow{3}{*}{$\begin{array}{l}\text { IV. Matrix of the } \\
\text { NP }\end{array}$} & 1 & Normal gelatinous appearance \\
\hline & 2 & Slight condensation of the extracellular matrix \\
\hline & 3 & Moderate/severe condensation of the extracellular matrix \\
\hline
\end{tabular}

Table 2. Reparative score.

\begin{tabular}{|c|c|c|}
\hline Features & Score & Description \\
\hline \multirow{3}{*}{ Cell cloning } & 0 & No cell clones \\
\cline { 2 - 3 } & 1 & Mild/moderate cell cloning \\
\cline { 2 - 3 } & 2 & Extensive cell cloning \\
\hline \multirow{3}{*}{ Cell morphology } & 0 & No large, rounded cells with intense matrix staining \\
\cline { 2 - 3 } & 1 & Few large, rounded cells with intense pericellular matrix staining \\
\cline { 2 - 3 } & 2 & Many large, rounded cells with intense pericellular matrix staining \\
\hline
\end{tabular}

baseline measurement. Radiographs were digitally scanned and digitally stored using an image-capture software program. IVD height was expressed as DHI, which was calculated as previously described (Mwale et al., 2011). The average percent change in DHI of injected discs (both L2/3 and L4/5) was calculated for each postoperative disc as a ratio to its preoperative $\mathrm{DHI}[\% \mathrm{DHI}=$ (postoperative $\mathrm{DHI} /$ preoperative $\mathrm{DHI}) \times 100]$ and further normalized to the DHI of the non-punctured disc (L3/4) [normalized \%DHI $=$ (punctured \%DHI/nonpunctured $\% \mathrm{DHI}) \times 100]$. All radiographs were assessed by observers blinded to the experiments.

\section{MRI analyses}

In the second experiment, the dose finding study following sacrifice (Fig. 2b), MRI examinations on isolated spine segments were performed using a 7-Tesla BioSpec 70/30 (Bruker). The MRI degeneration grade of IVDs was classified according to the Pfirrmann grade (Pfirrmann et al., 2001) using T2 weighted sagittal images. The evaluations were performed by two observers blinded to the experimental groups. The average degeneration grade of injected discs (L2/3 and L4/5) and L3/4 discs as control was calculated.

\section{Histological analyses}

Midsagittal sections ( $5 \mu \mathrm{m}$ ) of each experimental IVD from rabbits after sacrifice were stained with either hematoxylin and eosin or safranin-O/fast green. An observer blinded to this experiment analyzed the histological sections and graded them using an established protocol (Table 1) (Chujo et al., 2006). Because the score of the outer AF was not different among groups, the reparative score defined in Table 2 was also assessed. The score was analyzed in the inner AF and in the NP. For each disc, the total disc score was calculated by the sum of cell cloning and morphology of both the NP and inner AF.

\section{Immunohistochemical analysis of type II collagen} Randomly selected samples injected with PBS or decoy $(100 \mu \mathrm{g})$ of 8 rabbits at 8 weeks after initial puncture were representatively used for immunohistochemical analysis. Samples were fixed, decalcified, and embedded in paraffin-wax for serial $5 \mu \mathrm{m}$ sectioning used for immunohistochemical analysis. Following hyaluronidase treatment $(2 \mathrm{mg} /$ $\mathrm{mL}, \mathrm{H} 3506$, Sigma-Aldrich) for $2 \mathrm{~h}$ and endogenous peroxidase inactivation, the sections were stained with 1 : 500 dilution monoclonal anti-human type II collagen antibody (II-4C11: Kyowa Pharma Chemical, 
Table 3. Primer information.

\begin{tabular}{|c|c|c|}
\hline Company & Target gene & Assay/catalog ID \\
\hline Biorad & I8S & qOcuCED0018100 \\
\hline Biorad & IL1B & qOcuCED0009632 \\
\hline Biorad & TNFA & qOcuCED0015500 \\
\hline Biorad & PTGS2 & qOcuCED0018228 \\
\hline Biorad & qMP3 & qOcuCID0006289 \\
\hline Biorad & IL6 & Primer sequence (from 5'to 3')
\end{tabular}

Toyama, Japan) for immunohistochemical analyses. Mouse IgG (DakoCytomation, Glostrup, Denmark) was used as the isotype or negative control. Sections were visualized using the universal immuno-enzyme polymer method [Histofine Simple Stain MAXPO (M); Nichirei Biosciences, Tokyo, Japan] and 3,3'-diaminobenzidine tetrahydrochloride (Dojindo, Tokyo, Japan), followed by counterstaining with Mayer's hematoxylin.

Nude rat disc xenograft-radiculopathy model To study the effect of NF- $\kappa$ B decoy on pain induction, two stepwise experiments were performed.

The first experiment was conducted to reveal the specificity of allodynia induction by tissues from degenerated and treated disc tissues (Fig. 10a). Rabbits were euthanized 8 weeks after the initial anular puncture (4 weeks after the PBS injection). Tissues from the non-AF area (original NP area) of the non-punctured discs, tissues from discs with PBS injection or NF- $\kappa$ B decoy $(10 \mu \mathrm{g})$ injection, and fat tissues near spines from rabbits, as described above, were collected and used as the source of xenograft. Because the border between the AF and NP became unclear 4 weeks after puncture, the next adjacent level was used as the reference to collect tissues from the non-AF area (original NP area). These tissues were explanted onto nude rat DRGs to test allodynia induction in the rat radiculopathy model as described by Kawakami et al. (2000) with modification as a xenograft transplantation model (Miyazaki et al., 2018). Female NIH-Foxn $1^{\text {rnu }}$ nude rats $(n=32$ for the first study and $n=40$ for the second study, $150-200 \mathrm{~g}$, 8 weeks-old) were used. Under general anesthesia, the right L5-DRG was exposed by partial laminectomy and facetectomy. Degenerated NP-area tissues (either L2/3 or L4/5) from anular-punctured and injected discs (either PBS or NF- $\kappa \mathrm{B}$ decoy), non-punctured, non-injected discs (L3/4), or fat tissues were placed as xenografts.

The aim of the second study (Fig. 10b) was to identify the dose-dependency of NF- $\kappa$ B decoy injection into the rabbit discs. The same protocol was applied for 40 nude rats using anular-puncture and injection of discs with PBS or NF- $\kappa$ B decoy $(0.1,1,10$, and $100 \mu \mathrm{g})$.

In these xenograft studies, the use of analgesia was avoided with careful consideration of the 3Rs strategy (Replacement, Reduction, Refinement). Body weight changes, movement of animals in the cage, and gait behavior were monitored daily to identify the severity of pain. No apparent changes in these parameters were observed during the study.

\section{Mechanical allodynia test: the von Frey test}

The von Frey test was performed at indicated days to investigate allodynia of nude rats for up to 3 weeks (Chaplan et al., 1994; Dixon, 1980). As described by Chaplan et al. (1994), von Frey testing was performed during the day portion of the circadian cycle only. Mid-plantar hind paws were stimulated to test hyperalgesia. The von Frey hair (Muromachi Kikai, Tokyo, Japan) was presented perpendicular to the plantar surface with sufficient force to cause slight buckling against the paw and held for approximately $7 \mathrm{~s}$. Withdrawal of the paw and flinching were considered positive responses. The value was evaluated as the $50 \%$ withdrawal threshold according to the up-down method. When rats expressed pain or allodynia, they responded to smaller filaments and the score value decreased.

Gene expression analyses of degenerated/treated rabbit disc tissues after injection

Total RNA in NP and AF tissues was extracted using bead disruption and Qiazol (Qiagen) with further 
purification with Qiazol (Qiagen), followed by chloroform separation using the MinElute Cleanup kit (Qiagen). Whole transcriptome cDNA libraries were synthesized using the QuantiTect Whole Transcriptome kit (Qiagen). After preamplification using SsoAdvanced ${ }^{\mathrm{TM}}$ PreAmp Supermix (Biorad), qRT-PCR using a SYBR Green kit (Qiagen) was carried out on a Rotor-Gene Q (Qiagen) for quantification of the mRNA. Gene expression for IL1B, IL6, TNF-A, ACAN, COL2A1, VEGF, PTGS2, NGF, and MMP3 in both NP and AF tissues was analyzed with standards using pre-designed primers (Table 3). Gene expression was calculated as the number of copies of each gene relative to that of $18 \mathrm{~S}$ and further normalized to relative gene expression in non-punctured discs (L3/4): the average of the nonpunctured control value is presented as 1. Data are presented on a Log scale.

\section{Statistical analysis}

Data are shown as mean \pm standard error of the mean. Two-way repeated-measures ANOVA with LSD as a post-hoc test was used to assess DHI and mechanical allodynia. One or two-way ANOVA with LSD test was used for gene expression analyses. The Kruskal-Wallis non-parametric test with a Bonferroni correction was used to assess histological reparative scores. Statistical analyses were performed using
SPSS (IBM). Statistical significance was established as $p<0.05$.

Power calculations have been made to determine the number of samples $(n)$ needed per experimental group sufficient to detect the desired primary difference between group means with significance $\mathrm{a}=0.05$ and power $\beta=0.8$, based on a previous study (Miyazaki et al., 2018).

\section{Results}

\section{NF- $\kappa B$ decoy injected into rabbit IVDs remained} in the discs for at least up to 4 weeks

The pharmacokinetics of NF- $\kappa \mathrm{B}$ decoy injected into rabbit IVDs was studied to reveal the fate of injected decoys. Various forms of NF- $\kappa$ B decoy, such as FAM decoy, ${ }^{3} \mathrm{H}-\mathrm{NF}-\kappa \mathrm{B}$ decoy and native NF- $\kappa \mathrm{B}$ decoy were used. FAM decoy enabled to track in detail the localization of NF- $\kappa \mathrm{B}$ decoy after injection using a confocal microscope. ${ }^{3} \mathrm{H}-\mathrm{NF}-\kappa \mathrm{B}$ decoy was visualized by whole-body autoradiography to evaluate its distribution. These labeled decoys were quantified after tissue solubilization. Finally, the absolute amount of native NF- $\kappa B$ decoy remaining in the discs was quantified by LC/MS/MS.

All forms of NF- $\kappa \mathrm{B}$ decoy were injected into rabbit IVDs in the same fashion. They were injected from a

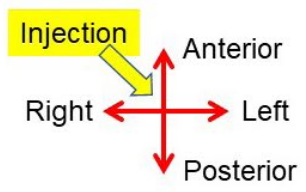

b

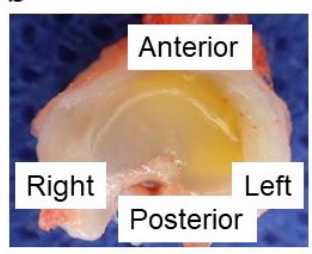

d

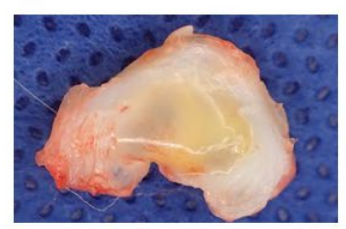

e
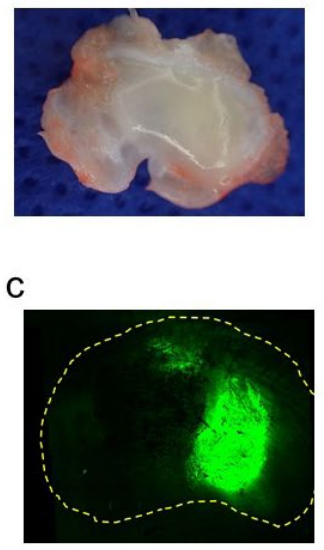

g

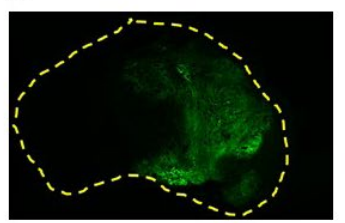

f

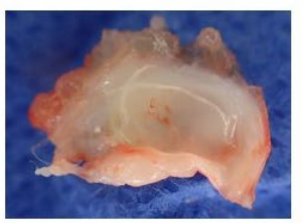

i

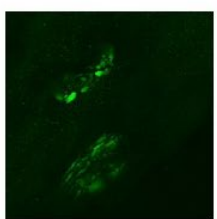

j

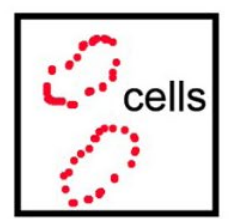

$\mathrm{h}$

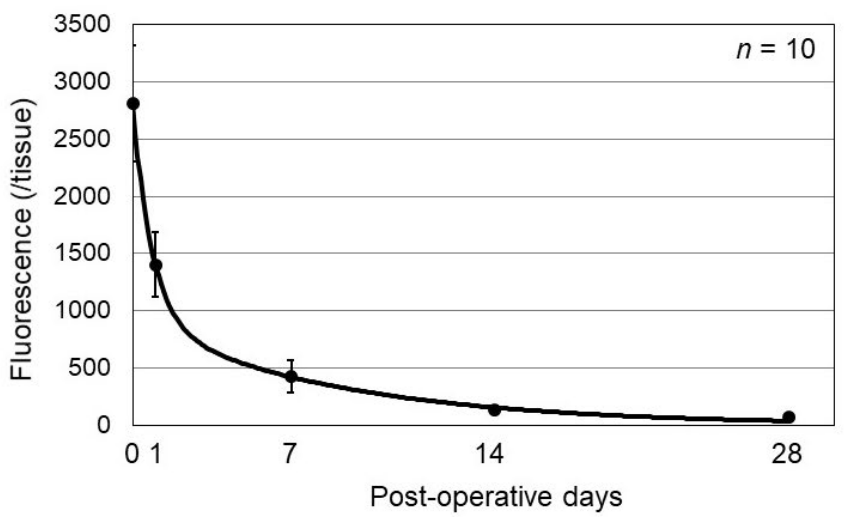

Fig. 3. Fluorescence analysis of FAM decoy. (a) Schematic showing the direction of injection. The black line represents the outline of the IVD. The injection was performed from the right anterior to the left side. (b) A macro-picture at day 1 . NF- $\kappa$ B decoy (yellow part) was clearly detected at the left side, which was compatible with the direction of injection. (c) Fluorescent microscopic image at day 1. The green signal is FAM decoy. The yellow dotted line represents the outline of the IVD. The distribution is the same as in the macro-image. (d) Macro-image at week 1. (e) Macro-image at week 2. (f) Macro-image at week 4 . (g) Fluorescent microscopic image at week 1. FAM decoy was seen at the left side, but the signal was low. (h) IVDs were papain digested. Fluorescent intensity of FAM decoy at each time point was quantified and plotted. (i) Detailed distribution of FAM decoy at high magnification. (j) Marked border of the 2 cells in i. 
the right anterior side to the center of the disc. Fig. 3a is a schematic showing the direction of the injection (arrow). $24 \mathrm{~h}$ after injection, NF- $\kappa \mathrm{B}$ decoy was clearly detected at the left side, which is compatible with the direction of injection $(3 \mathbf{b}, \mathbf{c})$. Observation of FAM decoy continued at 1, 2, and 4 weeks after injection (Fig. 3d-f). FAM decoy was detected up to 4 weeks after injection. Both decoys were detected in the area where they were observed at the $24 \mathrm{~h}$ time point. However, as the macro-pictures show, the later the time points were, the less FAM decoy was observed. At the 1-week time point, FAM decoy was slightly detected by fluorescent microscopy (Fig. 3g). However, the same conditions for fluorescence used $24 \mathrm{~h}$ after injection were not sufficient to visualize FAM decoy, suggesting that the amount of FAM decoy had decreased (compare Fig. 3c,g). To confirm the amount of FAM decoy that remained in the IVDs, the IVDs were digested by papain enzyme and quantified by fluorescent intensity (Fig. 3h). The absolute intensity of FAM decoy at the 4-week time point decreased to less than $5 \%$ of injected FAM decoy at 1 week. As the graph shows, the fluorescent intensity of FAM decoy followed a typical distribution and elimination pattern with a double exponential decay equation, as described in the Whole-body autography section. FAM decoy localization was further investigated at the cellular level using a higher magnification (Fig. 3i): FAM decoy was distributed throughout the entire cell and strongly in the nucleus.

How NF- $\kappa$ B decoy moved throughout the entire rabbit body was tested by using ${ }^{3} \mathrm{H}-\mathrm{NF}-\kappa \mathrm{B}$ decoy (Fig. $4)$. At the $24 \mathrm{~h}$ after injection into rabbit IVDs time point, ${ }^{3} \mathrm{H}-\mathrm{NF}-\kappa \mathrm{B}$ decoy was detected at the injection site and the surrounding area, which indicated that injected NF- $\kappa$ B decoy leaked out through the injection holes (Fig. 4a,b). ${ }^{3} \mathrm{H}-\mathrm{NF}-\kappa \mathrm{B}$ decoy was also detected in the bladder, suggesting that NF- $\kappa B$ decoy was eliminated through urine. $7 \mathrm{~d}$ after injection, ${ }^{3} \mathrm{H}-\mathrm{NF}-$ $\kappa \mathrm{B}$ decoy was detected only at the injection site (Fig. 4c). Interestingly, ${ }^{3} \mathrm{H}-\mathrm{NF}-\kappa \mathrm{B}$ decoy was detected up to $28 \mathrm{~d}$ after injection (Fig. $4 \mathrm{~d}$ ) and was quantified by radioisotope count. The quantification of ${ }^{3} \mathrm{H}-\mathrm{NF}-$ $\kappa \mathrm{B}$ decoy also followed an elimination/distribution pattern that is similar to the FAM decoy pattern (Fig. 3h and Fig. 5, red line). Finally, to investigate the remaining amount of NF- $\kappa \mathrm{B}$ decoy in IVDs, the amount of native NF- $\kappa$ B decoy was quantified by LC/ MS/MS. As observed by FAM decoy and ${ }^{3} \mathrm{H}-\mathrm{NF}-\kappa \mathrm{B}$ decoy experiments, the remaining amount of native NF- $\kappa$ B decoy fit a double-exponential-decay equation (Fig. 5, blue line). The half-life was calculated by the amount of ${ }^{3} \mathrm{H}-\mathrm{NF}-\kappa \mathrm{B}$ decoy remaining in IVDs. The corresponding elimination/distribution half-lives were $11.9 \mathrm{~h}$ and $618 \mathrm{~h}$, respectively.

\section{NF-кB-decoy recovered disc degeneration induced by anular puncture in the rabbit animal model}

A needle puncture into rabbit IVDs induces degeneration of IVDs and results in decreased IVD height (Masuda et al., 2005). The present study investigated whether NF- $\kappa \mathrm{B}$ decoy could change the course of IVD degeneration using the rabbit anular-puncture model. First, the long-term effect of NF- $\kappa$ B decoy was tested up to 24 weeks after injection (Fig. 6a). As previously reported, 4 weeks after an initial puncture, DHI decreased to around $20 \%$ of the original DHI. At this time point, there were no differences among groups. However, the a

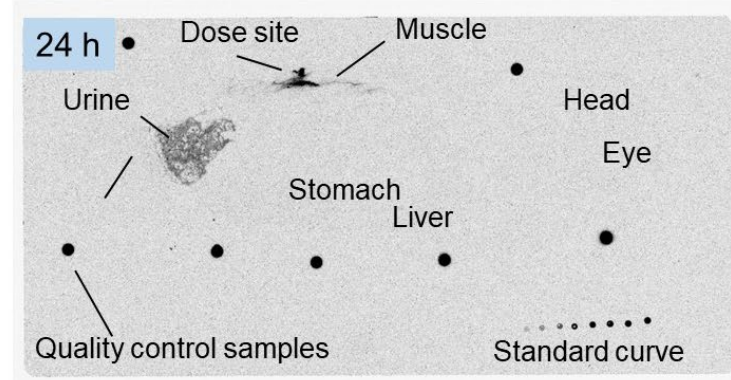

C

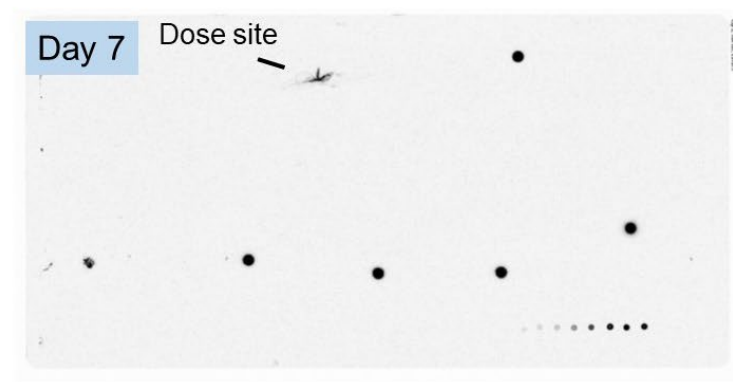

b

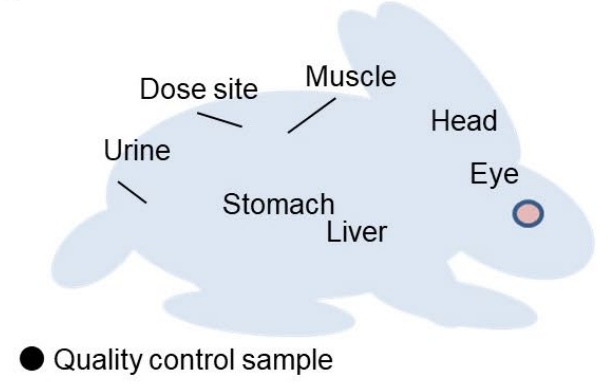

d

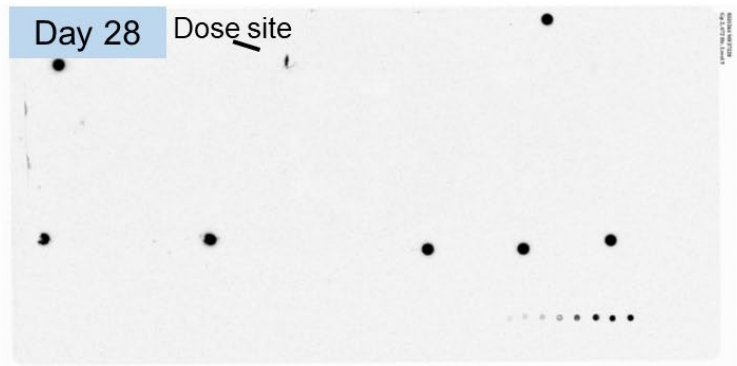

Fig. 4. Whole rabbit body autography. (a) Whole body autoradiography $24 \mathrm{~h}$ after injection of ${ }^{3} \mathrm{H}-\mathrm{NF}-\kappa \mathrm{B}$ decoy into rabbit IVDs. (b) Schematic representation of a. ${ }^{3} \mathrm{H}-\mathrm{NF}-\kappa \mathrm{B}$ decoy was clearly seen at the injection site as well as in the bladder. ${ }^{3} \mathrm{H}-\mathrm{NF}-\kappa \mathrm{B}$ decoy was seen only at the injection site at (c) day 7 and (d) day 28. 
disc height in the NF- $\kappa$ B-injected (decoy 1: $1 \mu \mathrm{g}$ ) group was significantly higher than that in the PBSinjected group $2(p<0.05)$ and 8 weeks $(p<0.01)$ post-injection, although the effect of this injection diminished 10 weeks post-injection. The strongest effect was observed with the $10 \mu \mathrm{g}$ NF- $\kappa \mathrm{B}$ injection (decoy 10: $10 \mu \mathrm{g}$ ), which achieved significance 4 weeks post-injection $(p<0.05)$ and was maintained throughout the study ( 24 weeks post-injection). Next, dose-effect was tested up to $100 \mu \mathrm{g}$ of NF- $\kappa \mathrm{B}$ decoy per disc (Fig. 6b). At the 16-week time point, compared to PBS injection, $10 \mu \mathrm{g}$ of NF- $\kappa \mathrm{B}$ decoy did not modify decreased DHI by anular puncture. However, $30 \mu \mathrm{g}$ of NF- $\mathrm{B}$ decoy significantly recovered DHI. The recovery rate of disc height was $+11.8 \%$. Interestingly, $100 \mu \mathrm{g}$ of NF- $\kappa \mathrm{B}$ decoy recovered DHI at the 10 -week time point and the recovery continued for at least up to the 16-week time point. The recovery rate of disc height was $+16.2 \%$ at the 16-week time point. Fig. 6c shows representative lumbar radiographs of each group.

\section{MRI assessment of disc degeneration grade}

12 weeks after PBS or NF- $\kappa \mathrm{B}$ decoy injection, L3/4 control discs in all groups exhibited no disc degeneration (Fig. 7). Anular puncture induced disc degeneration, but NF- $\kappa$ B decoy injection did not significantly reduce the degeneration grade compared to PBS. Although MRI of rabbits after 4 and 20 weeks were also examined following NF- $\kappa B$ decoy injection, there was no significant improvement in MRI grading by NF- $\kappa \mathrm{B}$ decoy injection compared to PBS injection (data not shown).

\section{Histological grading of disc degeneration}

Anular puncture induced significant disc degeneration. The injection of NF- $\kappa \mathrm{B}$ decoy did not show any significant effect on the overall histological grade of disc degeneration (Fig. 8a-c). On the other hand, for the reparative score, there were significant increases in cell cloning and morphological changes following NF- $\kappa B$ decoy injection. 4 weeks after $\mathrm{NF}-\kappa \mathrm{B}$ decoy injection, $100 \mu \mathrm{g}$ of $\mathrm{NF}-\kappa \mathrm{B}$ decoy injection significantly increased the reparative score of all elements of cell cloning and cell morphology scores both in the NP and the inner AF. The total reparative score was also significantly increased (Fig. 8d). Other doses at the 12-week time point showed a similar trend, but the differences were not statistically significant (Fig. 8e). While the histological grade after 24 weeks of NF- $\kappa \mathrm{B}$ injection did not show significant differences, $1 \mu \mathrm{g}$ of NF- $\kappa \mathrm{B}$ decoy injection significantly increased the reparative score of cell cloning in the NP and inner AF (Fig. 8f). Fig. $8 \mathrm{~g}$ shows representative sections of rabbit IVDs 4 weeks after injection. PBS injection did not increase rounded cloned cells and fibrous tissue was observed. However, $100 \mu \mathrm{g}$ of NF- $\kappa \mathrm{B}$ decoy increased cell cloning and matrix staining around rounded cells.

Because these cloned cells appeared chondrocytic or fibrochondrocytic, surrounded by dense matrix rich with proteoglycan, type II collagen was stained to identify cell characteristics (Fig. 9). Type II collagen was not strongly stained in the non-punctured discs (not shown) but was observed in degenerated IVDs. In the PBS-injected IVDs, type II collagen was less observed in the NP area than in the AF area (Fig. 9a). On the other hand, in NF- $\kappa$ B decoy $(100 \mu \mathrm{g})$-injected IVDs, type II collagen was clearly stained in the NP (Fig. 9b). This result suggested that cloned cells shared the characteristics of chondrocytic cells.

\section{NF- $\kappa$ B decoy reduced pain response in the "pain} sensor" nude rat xenograft-radiculopathy model NF- $\kappa$ B decoy was hypothesized to attenuate inflammatory responses in rabbit IVDs and reduce the pain response in the nude rat xenograftradiculopathy model compared to PBS-injected controls. The mechanical allodynia in nude rats was evaluated by the von Frey test. First, the specificity of allodynia induction by xenograft and the effect of NF- $\kappa$ B decoy injection in the rabbits was studied.

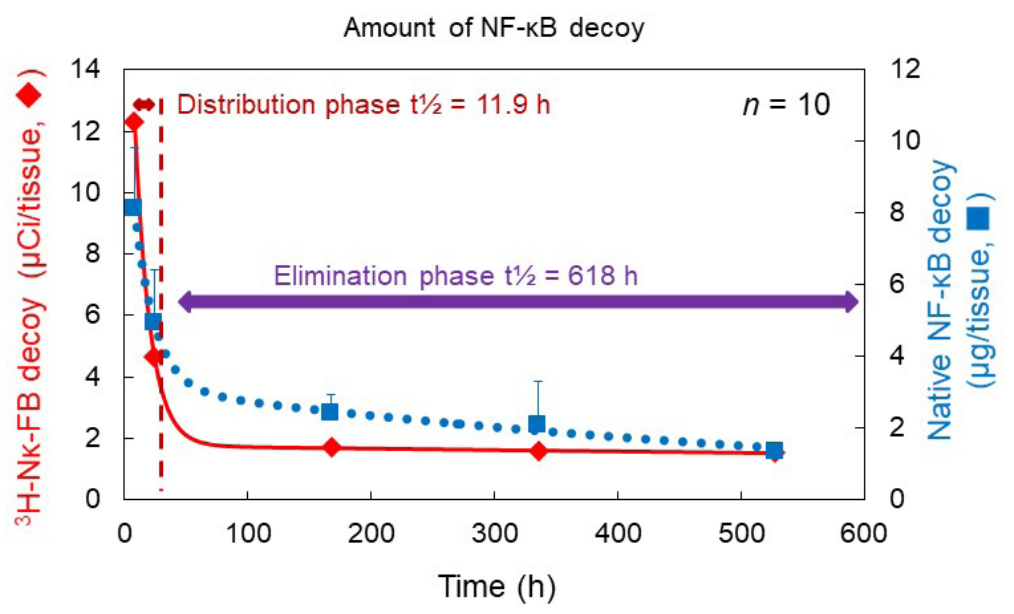

Fig. 5. The amount of remaining NF- $\mathrm{B}$ decoy after injection into rabbit IVDs. The amount of remaining decoy in the IVD post-injection obtained by a liquid scintillation counter analysis of radiolabeled decoy $\left({ }^{3} \mathrm{H}-\mathrm{NF}-\kappa \mathrm{B}\right.$ decoy) (red line) and LC/MS/MS measurements of native NF- $\kappa \mathrm{B}$ decoy (blue line). 


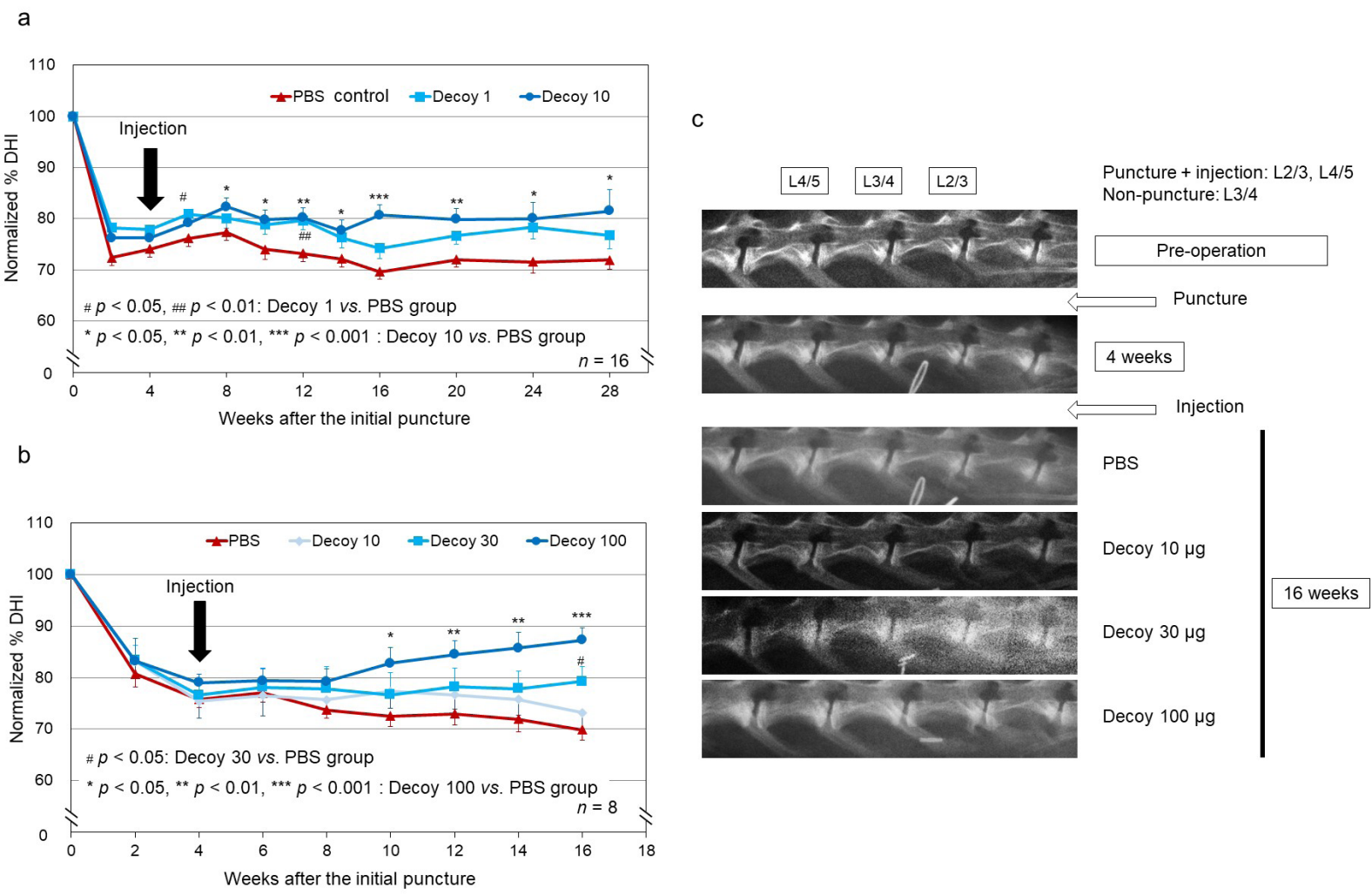

Fig. 6. Radiographic analyses of the effect of NF- $\kappa B$ injection on lumbar disc height in the rabbit anular-puncture model. (a) Change in DHI after anular puncture and injections of either PBS or NF- $k \mathrm{~B}$ (long-term study up to 28 weeks after initial puncture). Decoy 10: $10 \mu \mathrm{g} / \mathrm{disc}$ of NF- $\kappa \mathrm{B}$ decoy. Decoy 1: $1 \mu \mathrm{g} /$ disc. ${ }^{*} p<0.05,{ }^{* *} p<0.01,{ }^{* * *} p<0.001$ decoy 10 vs. PBS, ${ }^{*} p<0.05,{ }^{*} p<0.01$ : decoy 1 vs. PBS. (b) Change in DHI after anular puncture and injection of either PBS or NF- $\kappa B$ (dose study up to 16 weeks after initial puncture). ${ }^{*} p<0.05,{ }^{* *} p<0.01,{ }^{* * *} p<0.001$ vs. PBS. (c) Representative lateral radiogram of a rabbit lumbar spine before (pre-operative), 4 weeks after anular puncture with an 18-Gauge needle, and 16 weeks after puncture [12 weeks after injections of PBS or NF-kB decoy (10, 30, or $100 \mu \mathrm{g} / \mathrm{disc})]$.

a

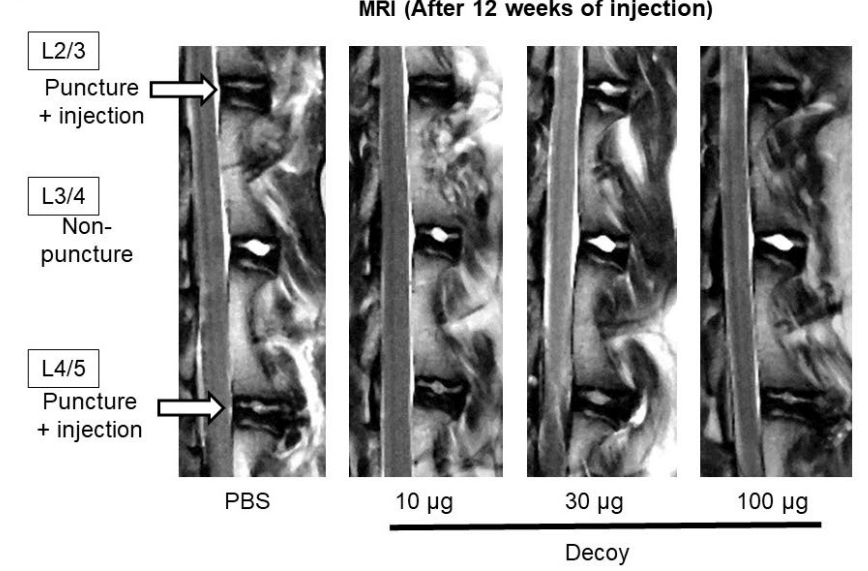

b

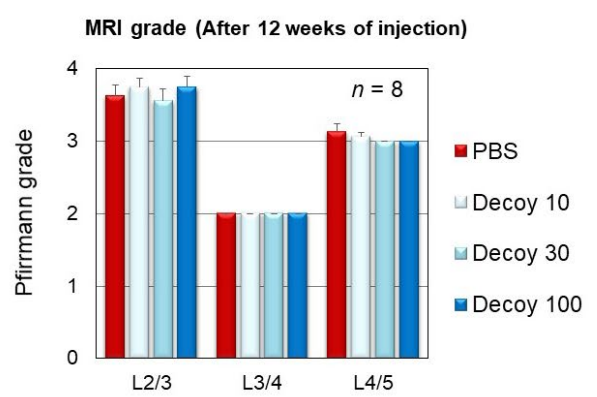

Fig. 7. The effect of NF- $\kappa B$ injection on MRI degeneration grade of the lumbar disc in the rabbit anularpuncture model. (a) MRI T2 weight sections in the sagittal plane 16 weeks after anular puncture [12 weeks after injections of PBS or NF- $k B$ (10, 30, or $100 \mu \mathrm{g} / \mathrm{disc})]$. (b) Pfirrmann MRI grade scores of discs after PBS or NF- $\mathrm{BB}$ injections. Data are expressed as the mean \pm standard error of the mean. 
Before transplantation of rabbit tissues onto rat DRGs, no rats showed allodynia (Fig. 10a). 6 d after transplantation, rats in all groups showed significant allodynia. On day 9 and 13, punctured rabbit NP tissues with PBS injection developed significant and persistent allodynia, while the fat and non-punctured NP tissue group showed reduced allodynia. Importantly, allodynia in the punctured rabbit NP tissues in the NF- $\kappa \mathrm{B}$ decoy injection group was significantly reduced compared to that in the PBS group as high as to the level of fat and nonpunctured NP tissues. Next, the dose-effect of NF- $\kappa B$ decoy was tested (Fig. 10b). 7 d after transplantation, rats in all groups showed significant allodynia. PBSinjected NPs induced the most severe allodynia, while there was a significant attenuation with the 10 and $100 \mu \mathrm{g}$ NF- $\kappa$ B decoy-injected NPs. On day 10, all doses of NF- $\kappa$ B-decoy-injected NPs significantly improved rat allodynia compared to PBS-injected NPs $(0.1 \mu g, p<0.05$; all others, $p<0.01)$. On day 14, $\mathrm{NF}-\kappa \mathrm{B}$ decoy injection attenuated degenerated-NPinduced allodynia to almost the pre-transplant level, while rats transplanted with PBS-injected NP still showed allodynia. On day 21, all rats recovered from a

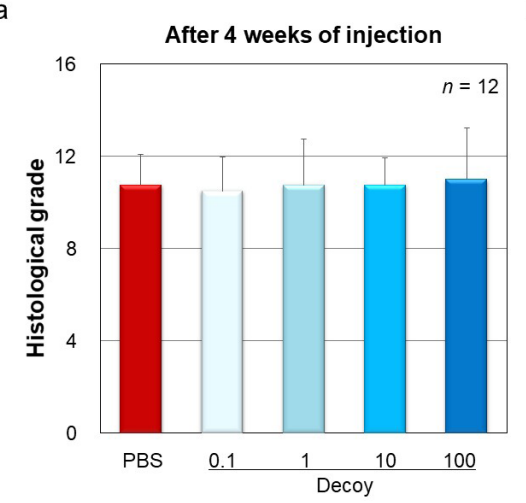

b

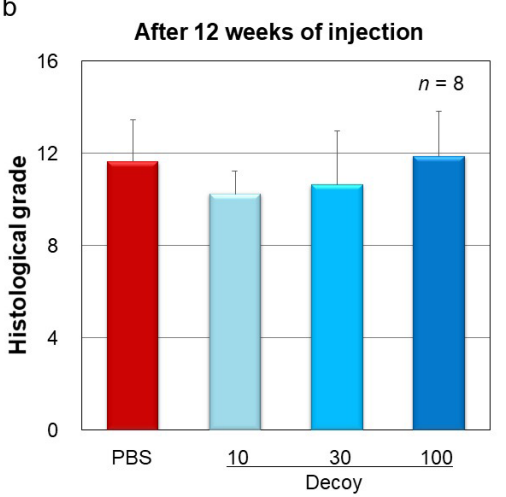

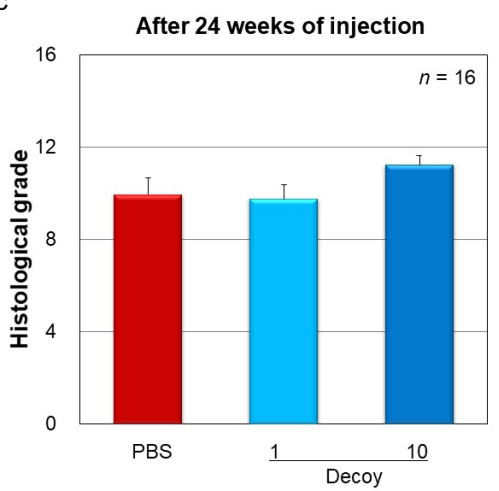
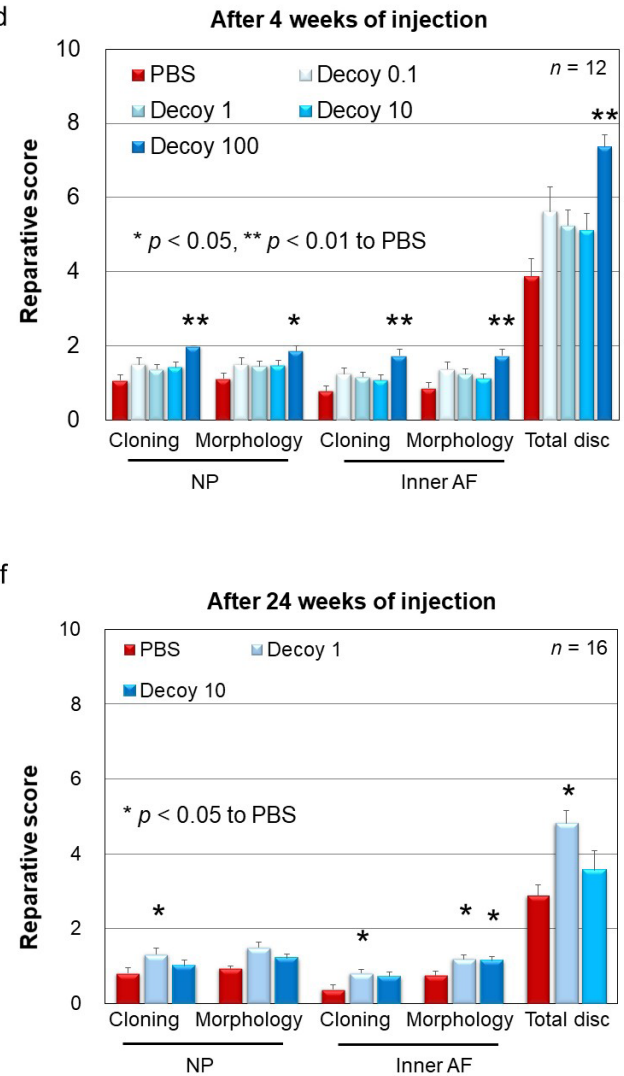

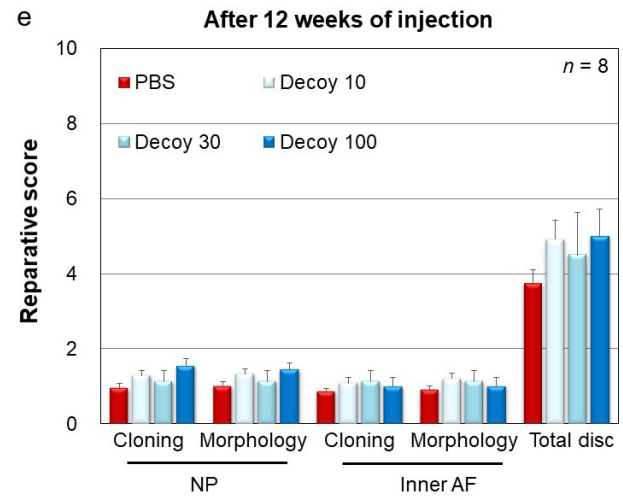

g

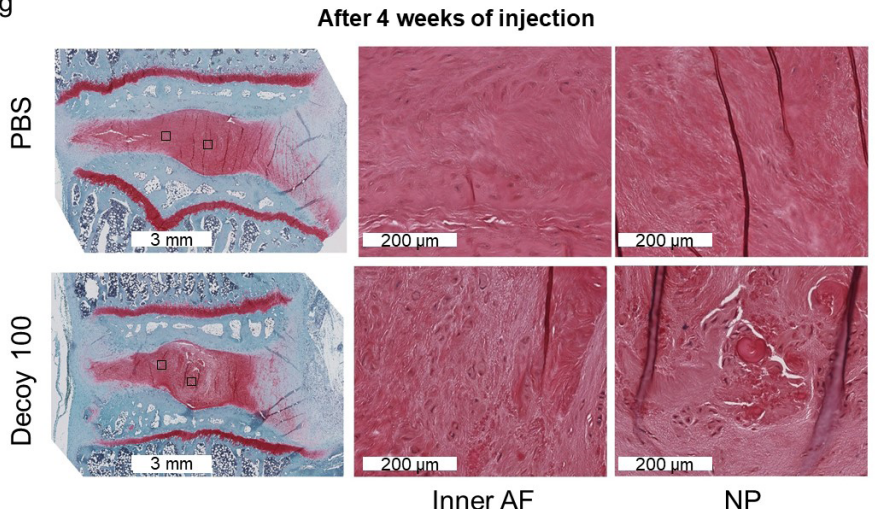

Fig. 8. The effect of NF- $\kappa B$ decoy injection on morphological changes of the lumbar disc in the rabbit anular-puncture model. Overall histological grading score (a) 4, (b) 12, and (c) 24 weeks after NF- $\kappa$ B decoy injection. Histological reparative score (cell cloning, cell morphology and total disc, presented in Table 2) (d) 4 , (e) 12 and (f) 24 weeks after NF-kB decoy injection. ${ }^{*} p<0.05$, ${ }^{* *} p<0.01$ compared to PBS injection. Data are expressed as mean \pm standard error of the mean $(n=8)$. (g) Representative safranin-O-stained sections of PBS-, and NF- $\mathrm{kB} 100 \mu \mathrm{g}$-treated discs. Scale bar: $3 \mathrm{~mm}$. Boxed highlighted area was enlarged in right pictures. (1) Inner AF of PBS injection, (2) NP of PBS injection, and (3) inner AF of decoy 100 injection, (4) NP of decoy 100 injection. Scale bar: $200 \mu \mathrm{m}$. 
allodynia, and there were no significant differences among groups. Two-way repeated-measures ANOVA revealed that NF- $\kappa$ B decoy $(1,10$, and $100 \mu \mathrm{g} /$ disc $)$ injection into rabbit IVDs significantly reduced rat allodynia in the nude rat xenograft-radiculopathy model $(p<0.01)$.

NF- $\kappa$ B decoy attenuated inflammatory gene expression levels in degenerated rabbit IVDs

NF- $\kappa$ B decoy binds to activated NF- $\kappa$ B and blocks subsequent activation of gene translation. Therefore, whether NF- $\kappa$ B decoy truly attenuated inflammatory gene expression levels was investigated. This is considered a plausible mechanism for recovering disc height in rabbits and reducing the pain response in the rat xenograft-radiculopathy model. Rabbits underwent IVD anular puncture and, 4weeks later, received various dosages of $\mathrm{NF}-\kappa \mathrm{B}$ decoy into punctured discs. Non-punctured and non-injected discs were used as internal controls to compare objectives. Gene expression levels were investigated at different time points, including 1-, 4-, and 12-

a

Isotype control (mouse lgG)

Type II collagen

PBS
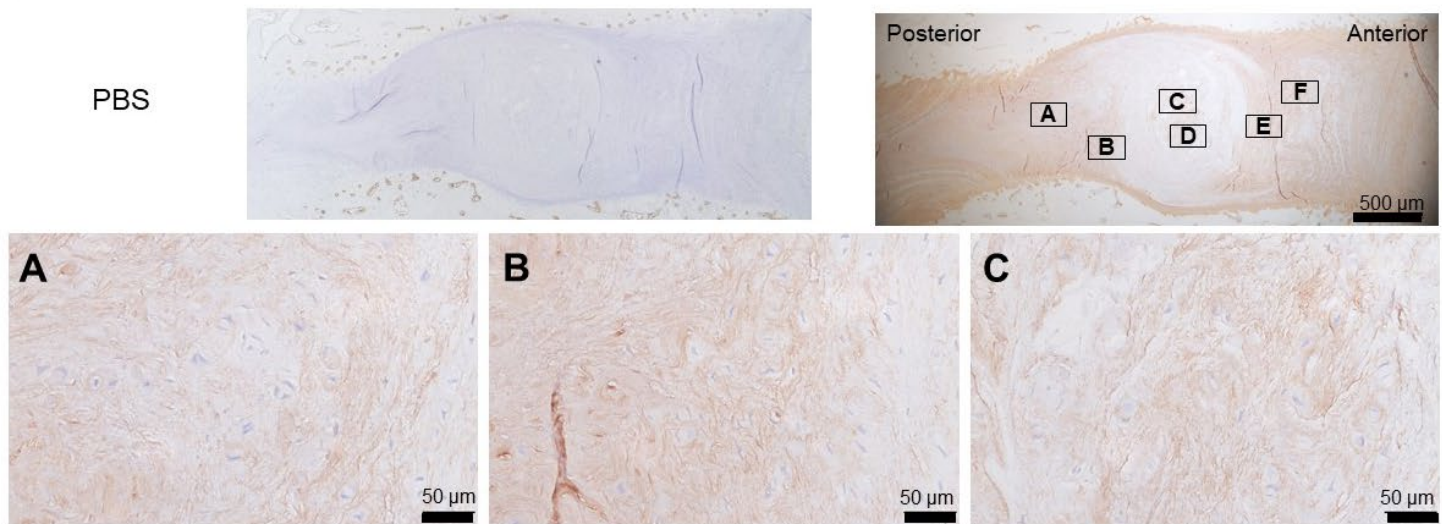

B

D
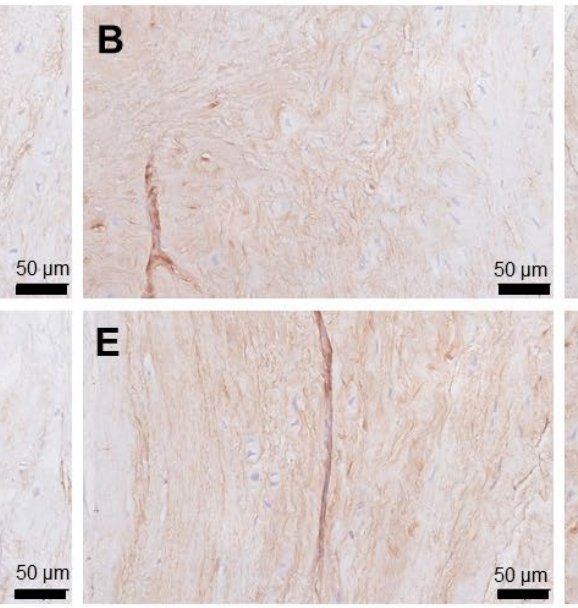

C

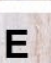

$50 \mu \mathrm{m}$

$50 \mu \mathrm{m}$

E

$\mathrm{F}$

b

Isotype control (mouse lgG)

Type II collagen
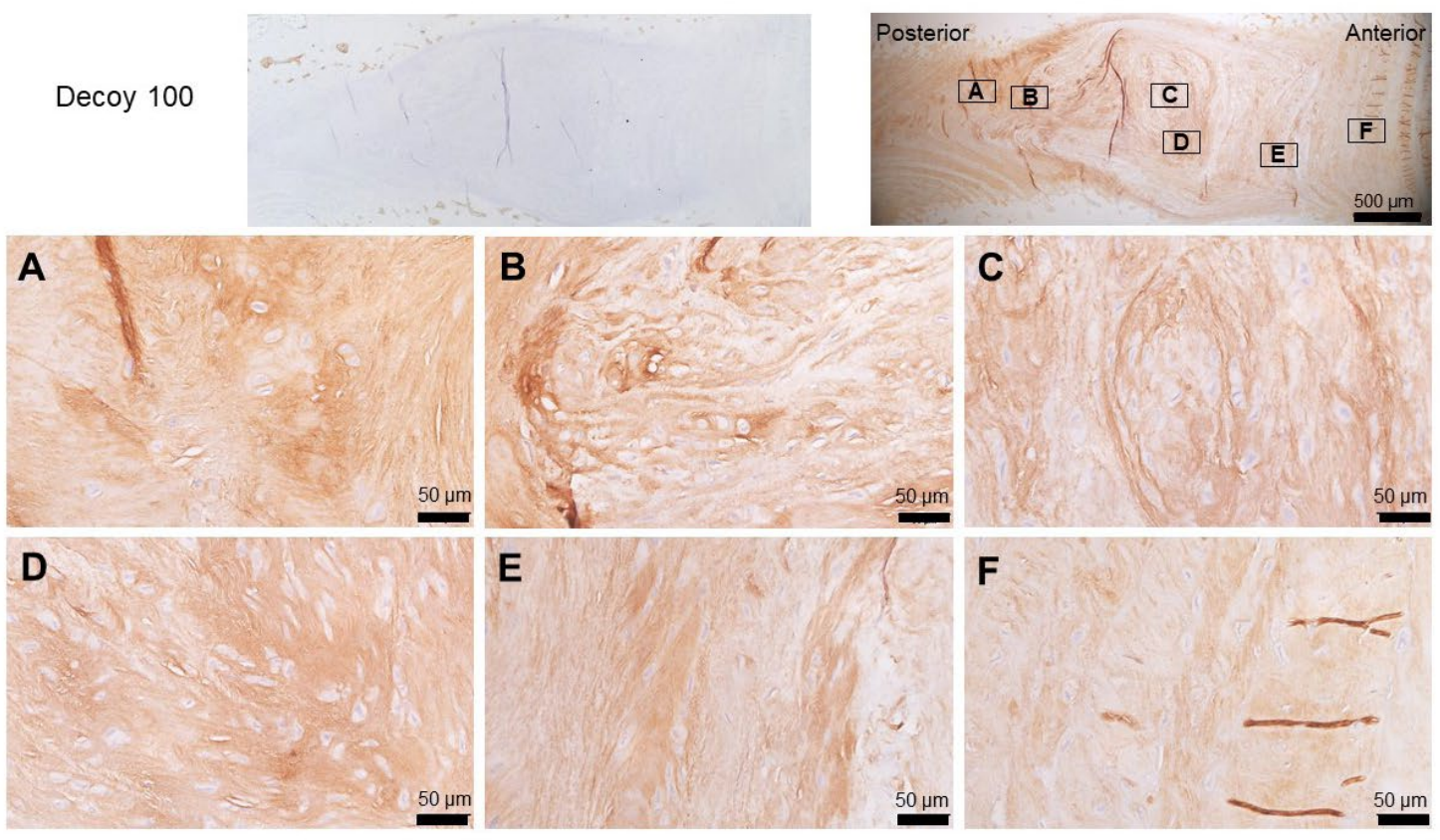

Fig. 9. The effect of NF- $\mathrm{B}$ decoy injection on type II collagen in the rabbit anular-puncture model. Type II collagen was stained on paraffin-wax sections. Representative sections of (a) PBS- and (b) NF- $\kappa$ B $100 \mu g-$ treated discs. Scale bar is indicated in each panel. 
week time points after NF- $\kappa$ B decoy injection. Upon euthanization of rabbits, discs were collected, and RNA was extracted. In the NP of anular-punctured IVDs at the 1-week after injection time point, mRNA levels of inflammatory cytokines, IL- 1 and TNF- $\alpha$, were significantly increased in the PBS group (Fig. 11a). Interestingly, although NF- $\kappa B$ decoy $(100 \mu g)$ reduced the expression levels of IL-1 and TNF- $\alpha$ from those of the PBS group (difference not statistically significant), lower doses of NF- $\kappa$ B decoy (10 $\mu \mathrm{g}$ and $30 \mu \mathrm{g})$ significantly reduced IL-1 level compared to the PBS group. The mRNA level of MMP3 was also slightly lower in NF- $\kappa \mathrm{B}$ decoy $(10 \mu \mathrm{g}$ and $30 \mu \mathrm{g})$ groups than in the PBS group $(p=0.06$ and $p=0.07$, respectively). There was no significant difference in NGF expression between the PBS group and the NF$\kappa B$ decoy groups in the NP. However, in the AF, the level of NGF mRNA was significantly lower in the NF- $\kappa$ B decoy $(10 \mu g)$ group than in the PBS group (Fig. 11b). NF- $\kappa$ B decoy (30 $\mu \mathrm{g})$ injection tended to reduce NGF mRNA expression levels $(p=0.07) .4$ weeks following injection, in the NP, mRNA levels of most inflammatory cytokines were increased by anular puncture (Fig. 11c, PBS group). IL-1 mRNA level, which was significantly increased by puncture at the 1-week time point, was still significantly higher in the PBS group than in the non-punctured control at the 4-week time point. The increased level of IL-1 was significantly suppressed by NF- $\kappa B$ decoy injection. Additionally, the mRNA level of TNF- $\alpha$ was significantly reduced by NF- $\kappa$ B decoy injection. This result was also observed in PTGS2 mRNA expression. There was a tendency for suppression of $M M P 3$ mRNA expression by NF- $\kappa$ B decoy injection at the 1-week time point; however, at the 4-week time point, MMP3 mRNA level was significantly attenuated by NF- $\kappa B$ decoy $(1 \mu g)$. In the AF (Fig. 11d), there were no significant differences in gene expression levels. At the 12-week time point after injection, there was a significant difference only in VEGF expression level in the NP (Fig. 11e). VEGF level was significantly increased in the PBS group, but NF- $\kappa$ B decoy reduced VEGF expression level. In the AF (Fig. 11f), while there was no significant difference for all genes of interest, ACAN ( $p=0.098)$ and COL2A1 $(p=0.060)$ expression levels tended to be increased by NF- $\kappa B$ decoy injection $(30 \mu \mathrm{g})$ compared to PBS control, which was not increased at all in the NP.

\section{Discussion}

The goal of the present study was to evaluate the efficacy of NF- $\kappa$ B decoy for degenerated IVD treatment at the clinical level. Because blood circulation to IVDs is extremely poor (Fontana et al., 2015), systemic administration may not be an appropriate candidate for degenerated-IVD treatment. Therefore, the intradiscal injection of NF$\kappa \mathrm{B}$ decoy as a drug delivery system was tested. To test NF- $\kappa$ B decoy as a possible therapeutic agent, first, how long NF- $\kappa$ B decoy remained within the IVDs was examined. Then, it was tested whether NF- $\kappa B$ decoy affected rabbit IVD degeneration induced by an anular puncture. Next, the ability of NF- $\kappa$ B decoy to reduce pain response was tested using the "pain sensor" nude rat xenograft-radiculopathy model, as previously published (Miyazaki et al., 2018).

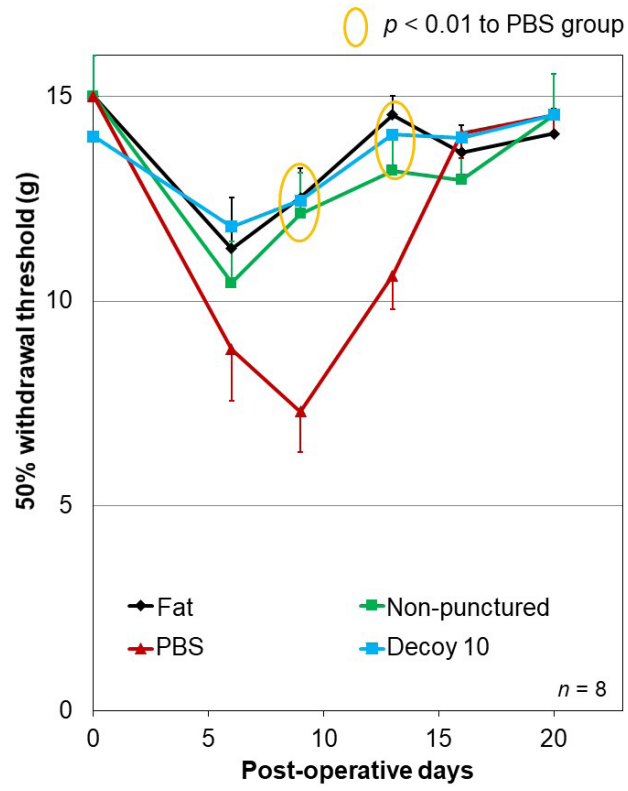

b

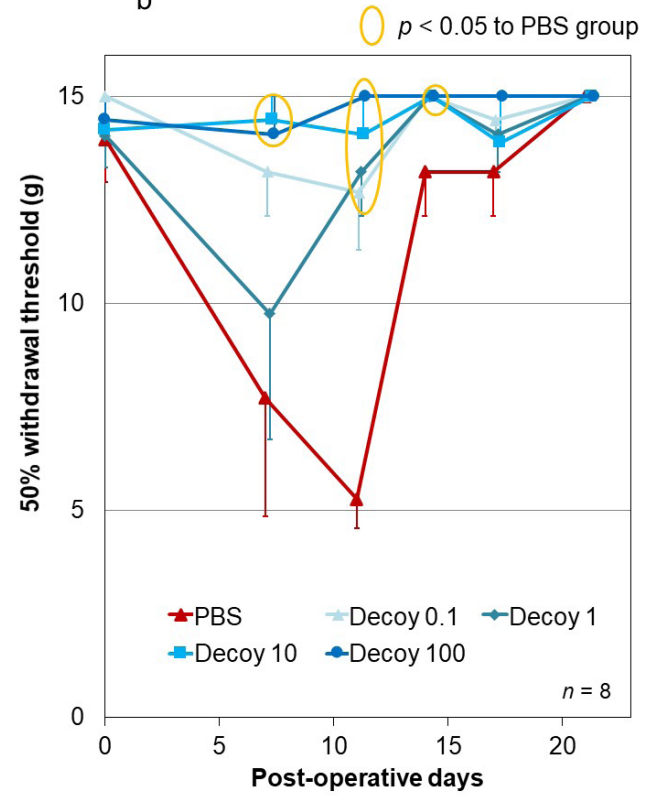

Fig. 10. von Frey analysis in the nude rat xenograft-radiculopathy model. (a) PBS- or NF- $\kappa B$ decoy $10 \mu g$-injected degenerated rabbit NP tissues, non-punctured rabbit NP tissues and rabbit fat tissues were transplanted on nude rat DRGs. (b) PBS- and various doses of NF- $\kappa$ B decoy-injected degenerated rabbit NP tissues were transplanted on nude rat DRGs. The paw withdrawal threshold of nude rats was measured using von Frey filaments to assess mechanical allodynia for up to 3 weeks after xenograft surgery. Data are expressed as the mean \pm standard error of the mean $(n=8)$. 
Finally, it was investigated whether NF- $\kappa$ B decoy truly modified puncture-induced gene expression levels in the rabbit degenerated IVDs. The present study reported that oligodeoxynucleotide NF- $\kappa B$ decoy persisted for at least up to 4 weeks in IVDs after injection and reduced clinical inflammatory responses, including recovering disc height, reducing pain response in the rat xenograft model and inflammatory gene expression levels.

To date, it has not been reported how long injected oligodeoxynucleotide or even other molecules remain within IVDs after a single intradiscal injection. In a series of experiments in rabbits, the present study showed that NF- $\kappa \mathrm{B}$ decoy was present up to 4 weeks after injection (Fig. 3-5). Results may suggest that a single injection could be effective for at least up to 4 weeks. However, whether NF- $\kappa B$ decoy is biologically effective for extended periods and the maximum time that NF- $\kappa B$ decoy remains within the IVDs is still unknown. Further investigation is needed to determine long-term biological activity.
The distribution study using the FAM-labeled decoy indicated that NF- $\kappa$ B decoy distributed throughout cells but was predominantly found within the nucleus. NF- $\kappa$ B decoy that binds to activated NF$\kappa \mathrm{B}$ in the cytoplasm (non-functional), free NF- $\kappa \mathrm{B}$ decoy, and activated NF- $\kappa \mathrm{B}$, all translocate to the nucleus. Within the nucleus, free NF- $\kappa \mathrm{B}$ decoys can bind activated NF- $\kappa$ B. Therefore, the NF- $\kappa$ B decoy blocks NF- $\kappa$ B binding to the DNA in the nucleus, resulting in the blocking of gene transcription (Fig. $1)$. The spatial distribution of the injected NF- $\kappa B$ decoy in IVD 4 weeks after injection showed that the labeled NF- $\kappa$ B decoy was located in the NP area from the center to the opposite side of the injected point. Although this could be seen immediately after injection of the contrast materials in clinical discograms, the diffuse distribution of the contrast was usually observed after $1 \mathrm{~d}$. It is important to note that this distribution study was performed using the naïve rabbit IVD, thus the exact distribution of injected molecules may differ in the human
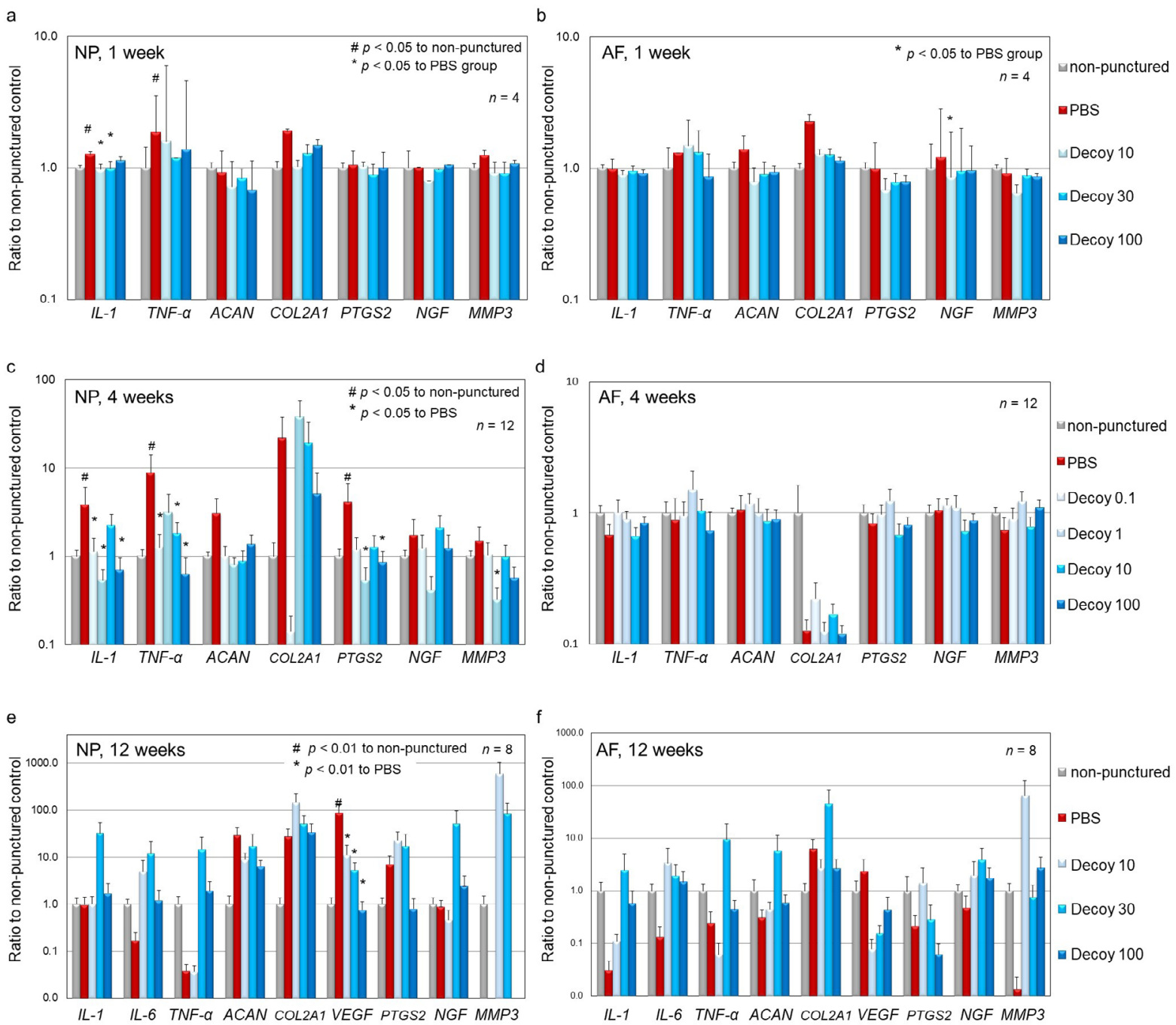

Fig. 11. Gene expression analysis of the IVD after injection of either PBS or various doses of NF- 1 B decoy by qRT-PCR. 1-week data in the (a) NP and (b) AF. 4-week data in the (c) NP and (d) AF. 12-week data in the NP (e) and AF (f). Gene expressions were calculated as the number of copies of each gene relative to those for 18S. Normalized gene expressions are represented on a Log scale. Data are expressed as mean \pm standard error of the mean. One-way analysis of variance with LSD as a post-hoc test was used. 
degenerated IVD. If rabbits with disc degeneration were used, the diffusion of NF- $\kappa B$ decoy to the entire $\mathrm{NP}$ area might occur, as seen in the human discogram. In addition, the volume of injection and speed may affect the distribution pattern. The careful selection of these parameters is critical for human application.

Experiments to investigate the amount of NF- $\kappa B$ decoy remaining showed that all 3 types of NF- $\kappa B$ decoy fit a double exponential decay equation. In the first distribution phase, NF- $\kappa B$ decoy spread throughout the IVD; some could either be rapidly distributed to the circulation through the endplate, while some might leak out of the IVD through the injection puncture. In the second phase, the NF$\kappa B$ decoy was gradually eliminated. NF- $\kappa B$ decoy was also detected in the bladder, suggesting that it was eliminated through the kidney to the urine. There are some concerns about side effects that are generally independent of sequence-related effects. For example, prolongation of activated partial thromboplastin time, hepatocellular degeneration, and renal dysfunction due to oligonucleotides have been reported (Levin, 1999). Most of these effects are reported as dose-dependent in the systemic circulation. Interestingly, 1 week after injection, NF$\kappa \mathrm{B}$ decoy was only detected in the injected IVDs. This suggested that NF- $\kappa B$ decoy might continue to be effective in IVDs but would not affect other regions for an extended period; that is, side effects in other body parts, if any, would be limited. The concentration of NF- $\kappa B$ decoy in the blood after injection was below sensitivity of the assay (data not shown). These results supported the contention that intradiscal injection of NF- $\kappa \mathrm{B}$ decoy is expected to be effective locally and with few systemic effects. Some injected liquid does leak from the injection holes due to the high pressure within the normal NP. Therefore, it was expected that radiolabeled NF- $\kappa B$ decoy would be detected not only inside IVDs but also around injection sites (Fig. 4). Another mechanism for oligodeoxy nucleotides disappearance is degradation/translocation into the nucleus (Levin, 1999). In the present study, double strands bound by hydrogen bonds and phosphorothioate nucleic acid analogs were used to protect nuclease degradation. The use of modified oligodeoxy nucleotides may have contributed to the long half-life of NF- $\mathrm{BB}$ decoy.

To test the efficacy to treat degenerated IVDs, the DHI was measured to observe how puncture and subsequent NF- $\kappa$ B decoy affected IVDs using X-ray images. As previously shown (Masuda et al., 2005), puncture alone caused the narrowing of IVD height. While the first long-term study showed that a $10 \mu \mathrm{g} /$ disc injection recovered disc height, in the second dose study, a $10 \mu \mathrm{g}$ injection of NF- $\kappa \mathrm{B}$ decoy was not sufficient. In the dose study, $100 \mu \mathrm{g} /$ disc NF- $\kappa B$ decoy injection recovered disc height and $10 \mu \mathrm{g} /$ disc of NF- $\kappa$ B decoy suppressed further disc height loss (Fig. 6). The dose response of NF- $\kappa B$ decoy dose between the long-term study and the dose study in the disc height analysis was not consistent. The results of each experiment indicated that NF- $\kappa B$ decoy injection was effective for disc height recovery in a dose-dependent manner, but lower doses were not consistently effective, suggesting that the lower dose had a marginal effect. Although experiments were conducted very carefully, this could be due to possible batch differences in NF- $\kappa \mathrm{B}$ decoy, animal sources, and housing conditions given the multiple institution sites involved, which is a limitation of the study. The MRI analysis did not show significant improvement by NF- $\kappa B$ decoy injection compared to PBS injection. Previously, by MRI assessment, a single injection of GDF6 was shown to protect against degenerative changes after anular puncture (Miyazaki et al., 2018). MRI Pfirrmann grading is defined by disc height and the signal intensity that primarily represents water content and proteoglycans. GDF6 may improve water content during the regenerative process. Although DHI was improved by NF- $\kappa$ B decoy injection, results indicated that there might be a different recovery mechanism from GDF6. Histological grading suggested that NF$\kappa \mathrm{B}$ decoy injection accelerated cell morphological reparative changes, especially in the inner AF; this may support the recovery of disc height after NF- $\kappa B$ decoy injection. Cell morphological reparative change results showed some inconsistency. In Fig. 8d, the $\mathrm{NF}-\kappa \mathrm{B}$ decoy 100 group had the highest reparative score after 4 weeks of injection, but no difference was observed after 12 weeks (Fig. 8e), while the decoy 1 group showed the highest score (Fig. 8f). First, due to the limited housing capacity, the experiments were divided into several series. Second, it is possible that the histological examination at the midsagittal center may have missed histological changes due to possible off-center distribution of injected decoys. However, overall results suggested that NF- $\kappa \mathrm{B}$ decoy affected cell morphology compared to PBS control.

In the intact IVD, chondrocytes originate and migrate from the cartilage endplate with aging (Kim et al., 2003). In growth factor studies using the anular-puncture model, the migration of cells from the inner AF and cartilage endplates is often found (Chujo et al., 2006; Miyazaki et al., 2018). The present study shared the same pattern with increased type II collagen deposition in the NP area (Fig. 9). Although stem cells or progenitor cells have been reported to originate from end plates (Lyu et al., 2019) it is not clear whether cloning cells originate from stem/progenitor cells; this was beyond the scope of the study. In the present study, the gene expression analysis did not show a significant increase in ACAN and COL2A1, but there was a tendency towards an increase only in the AF 12 weeks after injection ( $A C A N, p=0.098$; COL2A1, $p=0.060$ ). Histological findings warrant further biochemical quantification of protein levels of aggrecan and type II collagen in future studies. The most important outcome in the treatment of degenerated IVD disease is pain reduction. In a clinical situation, X-ray or even MRI images do not correlate with the patient's pain. Thus, to evaluate 
NF- $\kappa$ B decoy efficacy for clinical use, it is essential to investigate its effect on pain. However, there are no standardized animal models to evaluate discogenic pain. Rabbits, in particular, are not an optimal animal species to evaluate pain reduction because they tend to hide the pain response. Rats might prove to be an appropriate animal model as they have been used to evaluate pain with the von Frey test. In the present study, the nude rat xenograft-radiculopathy model was used to detect test tissue-induced pain response (Kawakami et al., 2000; Miyazaki et al., 2018). Kawakami et al. (2000) discussed that allodynia was caused by chemical factors released from the ectopic NP tissue. Even non-punctured NP tissues induced allodynia in the study. Recent studies have shown that punctured degenerated IVDs are considered to be inflammatory-rich tissues (Rider et al., 2019). To overcome the shortcomings of the rabbit disc degeneration model for pain assessment, rabbit tissues from the NP area, which are inflammatoryrich, are transplanted onto rat DRGs; thus, exposing DRGs to an inflammatory environment that causes pain (Fontana et al., 2015; Huang et al., 2017; Wang et al., 2017). The present study hypothesized that inflammation-rich disc tissue would cause pain in the rat xenograft-radiculopathy model, and if the inflammation was reduced by NF- $\kappa B$ decoy, the rats would feel less pain as seen in the GDF6-treated disc (Miyazaki et al., 2018). In the study's model, punctureinduced degenerated rabbit IVDs caused allodynia in all rats around $7 \mathrm{~d}$. However, rats in which PBSinjected degenerated rabbit discs were transplanted showed stronger allodynia than those rats in which NF- $\kappa \mathrm{B}$-decoy-injected degenerated rabbit discs were transplanted (Fig. 10). Among NF- $\kappa$ B decoy-injected IVDs, $0.1 \mu \mathrm{g}$ NF- $\kappa \mathrm{B}$ decoy had the least effect, and $100 \mu \mathrm{g}$ NF- $\kappa \mathrm{B}$ decoy showed the maximum effect on pain relief, suggesting that the effect of NF- $\kappa B$ decoy was dose-dependent. Because rabbit IVDs are larger than rat IVDs, molecular changes and morphological changes are more easily investigated and more accurately investigated in rabbit IVDs than in rat IVDs. However, because rabbits do not express pain to a great degree, this two-step disc xenograftradiculopathy model could be effective in providing a novel assessment method for the administration of new reagents for IVD disease by linking the inflammatory status of tissues with pain induction in the rat.

$\mathrm{NF}-\kappa \mathrm{B}$ is a transcription factor that regulates various genes' expression, including inflammatory genes. The main pathway of NF- $\kappa \mathrm{B}$ decoy is to block NF- $\kappa B$ from activating inflammatory genes' expression. In the present study, NF- $\kappa \mathrm{B}$ decoy attenuated inflammatory genes' expression in vivo (Fig. 11). TNF- $\alpha$ and IL-1 are activated in many inflammatory diseases, such as rheumatoid arthritis, as well as in degenerated IVDs. These two genes were activated in IVDs by anular puncture and NF- $\kappa B$ decoy injection reduced their expression levels. Thus, $\mathrm{NF}-\kappa \mathrm{B}$ decoy was effective in blocking inflammatory gene expression in vivo. The suppression of an inflammatory gene is a reasonable explanation for the recovery of disc height in the rabbit anular-puncture model and for a reduction in pain response in the rat xenograft-radiculopathy model.

The interim results of the Phase $1 b$ clinical trial of an intradiscal injection of NF- $\kappa \mathrm{B}$ decoy (ClinicalTrials.gov Identifier: NCT03263611) indicate that the intradiscal injection of NF- $\kappa \mathrm{B}$ decoy is welltolerated, with no serious adverse events during the 12-month follow-up. The efficacy data on pain (VAS scale) shows $97.5 \%$ reduction in the highdose group (10 mg/disc) compared to the placebo group, which shows $14 \%$ reduction (Web ref. $1)$. Patients injected with NF- $\kappa \mathrm{B}$ decoy into IVDs show safety of the treatment and a dose-dependent improvement compared to patients injected with placebo. Interestingly, the disc height of the high dose group increased significantly compared to that of the control group, mirroring the present study preclinical result. Animal results in the distribution and efficacy studies shared similar characteristics with the clinical study. The results in the preclinical and clinical study suggest that the rabbit anular-puncture model and the two-step xenograft model are valid animal models to predict the outcome for the human clinical trial. Further clinical studies may reveal the correlation between the rabbit structural changes, such as MRI, and those in human patients.

\section{Acknowledgments}

The authors would like to thank T. Iino, T. Chujo, K. Cheng, and J. Huang for their generous assistance.

\section{References}

Akeda K, Ohishi K, Masuda K, Bae WC, Takegami N, Yamada J, Nakamura T, Sakakibara T, Kasai Y, Sudo A (2017) Intradiscal injection of autologous platelet-rich plasma releasate to treat discogenic low back pain: a preliminary clinical trial. Asian Spine J 11: 380-389.

Chaplan SR, Bach FW, Pogrel JW, Chung JM, Yaksh TL (1994) Quantitative assessment of tactile allodynia in the rat paw. J Neurosci Methods 53: 5563.

Chujo T, An HS, Akeda K, Miyamoto K, Muehleman C, Attawia M, Andersson G, Masuda K (2006) Effects of growth differentiation factor-5 on the intervertebral disc-in vitro bovine study and in vivo rabbit disc degeneration model study. Spine (Phila Pa 1976) 31: 2909-2917.

De Stefano D (2011) Oligonucleotides decoy to NF-kappaB: becoming a reality? Discov Med 12: $97-$ 105.

Dixon WJ (1980) Efficient analysis of experimental observations. Annu Rev Pharmacol Toxicol 20: 441462. 
Fontana G, See E, Pandit A (2015) Current trends in biologics delivery to restore intervertebral disc anabolism. Adv Drug Deliv Rev 84: 146-158.

Fukui D, Kawakami M, Matsumoto T, Naiki M (2018) Stress enhances gait disturbance induced by lumbar disc degeneration in rat. Eur Spine J 27: 205213.

Garcia JB, Hernandez-Castro JJ, Nunez RG, Pazos MA, Aguirre JO, Jreige A, Delgado W, Serpentegui M, Berenguel M, Cantemir C (2014) Prevalence of low back pain in Latin America: a systematic literature review. Pain Physician 17: 379-391.

Huang Y, Chen J, Jiang T, Zhou Z, Lv B, Yin G, Fan J (2017) Gallic acid inhibits the release of ADAMTS4 in nucleus pulposus cells by inhibiting p65 phosphorylation and acetylation of the NF- $\kappa B$ signaling pathway. Oncotarget 8: 47665-47674.

Ito K, Creemers L (2013) Mechanisms of intervertebral disk degeneration/injury and pain: a review. Global Spine J 3: 145-152.

Kawakami M, Tamaki T, Hayashi N, Hashizume H, Matsumoto T, Minamide A, Kihira T (2000) Mechanical compression of the lumbar nerve root alters pain-related behaviors induced by the nucleus pulposus in the rat. J Orthop Res 18: 257-264.

Khasabov SG, Wang JC, Simone DA, Strichartz GR (2017) A role for neurokinin-1 receptor neurons in the rostral ventromedial medulla in the development of chronic postthoracotomy pain. Pain 158: 1332-1341.

Kim KW, Lim TH, Kim JG, Jeong ST, Masuda K, An HS (2003) The origin of chondrocytes in the nucleus pulposus and histologic findings associated with the transition of a notochordal nucleus pulposus to a fibrocartilaginous nucleus pulposus in intact rabbit intervertebral discs. Spine (Phila Pa 1976) 28: 982-990.

Levin AA (1999) A review of the issues in the pharmacokinetics and toxicology of phosphorothioate antisense oligonucleotides. Biochim Biophys Acta 1489: 69-84.

Liacini A, Sylvester J, Li WQ, Huang W, Dehnade F, Ahmad M, Zafarullah M (2003) Induction of matrix metalloproteinase-13 gene expression by TNF-alpha is mediated by MAP kinases, AP-1, and NF-kappaB transcription factors in articular chondrocytes. Exp Cell Res 288: 208-217.

Ling J, Kumar R (2012) Crosstalk between NFkB and glucocorticoid signaling: a potential target of breast cancer therapy. Cancer Lett 322: 119-126.

Liu Y, Qu Y, Liu L, Zhao H, Ma H, Si M, Cheng L, Nie L (2019) PPAR-gamma agonist pioglitazone protects against IL-17 induced intervertebral disc inflammation and degeneration via suppression of NFkappaB signaling pathway. Int Immunopharmacol 72: 138-147.

Liu Y, Wei J, Zhao Y, Zhang Y, Han Y, Chen B, Cheng K, Jia J, Nie L, Cheng L (2017) Follistatin-like protein 1 promotes inflammatory reactions in nucleus pulposus cells by interacting with the MAPK and NFkB signaling pathways. Oncotarget 8: 43023-43034.

Lyu FJ, Cheung KM, Zheng Z, Wang H, Sakai D,
Leung VY (2019) IVD progenitor cells: a new horizon for understanding disc homeostasis and repair. Nat Rev Rheumatol 15: 102-112.

Mantamadiotis T (2017) Towards targeting PI3K-dependent regulation of gene expression in brain cancer. Cancers (Basel) 9: 60. DOI: 10.3390/ cancers9060060.

Manthiram K, Zhou Q, Aksentijevich I, Kastner DL (2017) The monogenic autoinflammatory diseases define new pathways in human innate immunity and inflammation. Nat Immunol 18: 832-842.

Masuda K, Aota Y, Muehleman C, Imai Y, Okuma M, Thonar EJ, Andersson GB, An HS (2005) A novel rabbit model of mild, reproducible disc degeneration by an anulus needle puncture: correlation between the degree of disc injury and radiological and histological appearances of disc degeneration. Spine (Phila Pa 1976) 30: 5-14.

Masuda K, Imai Y, Okuma M, Muehleman C, Nakagawa K, Akeda K, Thonar E, Andersson G, An HS (2006) Osteogenic protein-1 injection into a degenerated disc induces the restoration of disc height and structural changes in the rabbit anular puncture model. Spine (Phila Pa 1976) 31: 742-754.

Matsuda N, Hattori Y, Jesmin S, Gando S (2005) Nuclear factor-kappaB decoy oligodeoxynucleotides prevent acute lung injury in mice with cecal ligation and puncture-induced sepsis. Mol Pharmacol 67: 1018-1025.

Meucci RD, Fassa AG, Faria NM (2015) Prevalence of chronic low back pain: systematic review. Rev Saude Publica 49: 1. DOI: 10.1590/S00348910.2015049005874.

Miyazaki S, Diwan AD, Kato K, Cheng K, Bae WC, Sun Y, Yamada J, Muehleman C, Lenz ME, Inoue N, Sah RL, Kawakami M, Masuda K (2018) ISSLS PRIZE IN BASIC SCIENCE 2018: Growth differentiation factor-6 attenuated pro-inflammatory molecular changes in the rabbit anular-puncture model and degenerated disc-induced pain generation in the rat xenograft radiculopathy model. Eur Spine J 27: 739751.

Mok SS, Masuda K, Hauselmann HJ, Aydelotte MB, Thonar EJ (1994) Aggrecan synthesized by mature bovine chondrocytes suspended in alginate. Identification of two distinct metabolic matrix pools. J Biol Chem 269: 33021-33027.

Molinos M, Almeida CR, Caldeira J, Cunha C, Goncalves RM, Barbosa MA (2015) Inflammation in intervertebral disc degeneration and regeneration. J R Soc Interface 12: 20150429.

Morishita R, Sugimoto T, Aoki M, Kida I, Tomita N, Moriguchi A, Maeda K, Sawa Y, Kaneda Y, Higaki J, Ogihara T (1997) In vivo transfection of cis element "decoy" against nuclear factor-kappaB binding site prevents myocardial infarction. Nat Med 3: 894-899.

Mwale F, Demers CN, Petit A, Roughley P, Poole AR, Steffen T, Aebi M, Antoniou J (2003) A synthetic peptide of link protein stimulates the biosynthesis of collagens II, IX and proteoglycan by cells of the intervertebral disc. J Cell Biochem 88: 1202-1213. 
Mwale F, Masuda K, Pichika R, Epure LM, Yoshikawa T, Hemmad A, Roughley PJ, Antoniou J (2011) The efficacy of Link $\mathrm{N}$ as a mediator of repair in a rabbit model of intervertebral disc degeneration. Arthritis Res Ther 13: R120. DOI: 10.1186/ar3423.

Nakamura H, Aoki M, Tamai K, Oishi M, Ogihara T, Kaneda Y, Morishita R (2002) Prevention and regression of atopic dermatitis by ointment containing NF- $\kappa \mathrm{B}$ decoy oligodeoxynucleotides in NC/Nga atopic mouse model. Gene Ther 9: 1221-1229.

Nemeth K, Deshpande R, Mathe Z, Szuak A, Kiss M, Korom C, Nemeskeri A, Kobori L (2015) Extrahepatic arteries of the human liver - anatomical variants and surgical relevancies. Transpl Int 28: 12161226.

Nguyen C, Boutron I, Baron G, Sanchez K, Palazzo C, Benchimol R, Paris G, James-Belin E, LefevreColau MM, Beaudreuil J, Laredo JD, Bera-Louville A, Cotten A, Drape JL, Feydy A, Ravaud P, Rannou F, Poiraudeau S (2017) Intradiscal glucocorticoid injection for patients with chronic low back pain associated with active discopathy: a randomized trial. Ann Intern Med 166: 547-556.

Murray CJL, GBD 2017 Disease and Injury Incidence and Prevalence Collaborators (2018) Global, regional, and national incidence, prevalence, and years lived with disability for 354 diseases and injuries for 195 countries and territories, 1990-2017: a systematic analysis for the Global Burden of Disease Study 2017. Lancet 392: 1789-1858.

Obata S, Akeda K, Imanishi T, Masuda K, Bae W, Morimoto R, Asanuma Y, Kasai Y, Uchida A, Sudo A (2012) Effect of autologous platelet-rich plasmareleasate on intervertebral disc degeneration in the rabbit anular puncture model: a preclinical study. Arthritis Res Ther 14: R241. DOI: 10.1186/ar4084.

Peng B, Pang X, Wu Y, Zhao C, Song X (2010) A randomized placebo-controlled trial of intradiscal methylene blue injection for the treatment of chronic discogenic low back pain. Pain 149: 124-129.

Pfirrmann CW, Metzdorf A, Zanetti M, Hodler J, Boos N (2001) Magnetic resonance classification of lumbar intervertebral disc degeneration. Spine (Phila Pa 1976) 26: 1873-1878.

Philpott HT, O’Brien M, McDougall JJ (2017) Attenuation of early phase inflammation by cannabidiol prevents pain and nerve damage in rat osteoarthritis. Pain 158: 2442-2451.

Raciborski F, Gasik R, Klak A (2016) Disorders of the spine. A major health and social problem. Reumatologia 54: 196-200.

Rider SM, Mizuno S, Kang JD (2019) Molecular mechanisms of intervertebral disc degeneration. Spine Surg Relat Res 3: 1-11.

Sainoh T, Orita S, Miyagi M, Inoue G, Kamoda H, Ishikawa T, Yamauchi K, Suzuki M, Sakuma Y, Kubota G, Oikawa Y, Inage K, Sato J, Nakata Y, Nakamura J, Aoki Y, Toyone T, Takahashi K, Ohtori S (2016a) Single intradiscal administration of the tumor necrosis factor-alpha inhibitor, etanercept, for patients with discogenic low back pain. Pain Med 17: 40-45.

Sainoh T, Orita S, Miyagi M, Inoue G, Yamauchi K, Suzuki M, Sakuma Y, Kubota G, Oikawa Y, Inage K, Sato J, Nakata Y, Aoki Y, Takahashi K, Ohtori S (2016b) Single intradiscal injection of the interleukin-6 receptor antibody tocilizumab provides short-term relief of discogenic low back pain; prospective comparative cohort study. J Orthop Sci 21: 2-6.

Samartzis D, Borthakur A, Belfer I, Bow C, Lotz JC, Wang HQ, Cheung KM, Carragee E, Karppinen J (2015) Novel diagnostic and prognostic methods for disc degeneration and low back pain. Spine J 15: 1919-1932.

Srebro D, Vuckovic S, Prostran M (2016) Participation of peripheral TRPV1, TRPV4, TRPA1 and ASIC in a magnesium sulfate-induced local pain model in rat. Neuroscience 339: 1-11.

Wang S, Liu C, Sun Z, Yan P, Liang H, Huang K, Li C, Tian J (2017) IL-1beta increases asporin expression via the NF-kappaB p65 pathway in nucleus pulposus cells during intervertebral disc degeneration. Sci Rep 7: 4112. DOI: 10.1038/s41598-017-04384-3.

Wang X, Wang H, Yang H, Li J, Cai Q, Shapiro IM, Risbud MV (2014) Tumor necrosis factor- $\alpha$ - and interleukin-1 $\beta$-dependent matrix metalloproteinase-3 expression in nucleus pulposus cells requires cooperative signaling via syndecan 4 and mitogenactivated protein kinase-NF- $\kappa$ B axis: implications in inflammatory disc disease. Am J Pathol 184: 25602572.

Zhongyi S, Sai Z, Chao L, Jiwei T (2015) Effects of nuclear factor kappa B signaling pathway in human intervertebral disc degeneration. Spine (Phila Pa 1976) 40: 224-232.

\section{Web References}

1. https://www.anges.co.jp/pdf_news/public/ i6EZwA6o96VYi5j3zC7mogUljhwnnseu.pdf [21-062021]

\section{Discussion with Reviewer}

Li Jin: How could this oligodeoxynucleotide apply to humans? Would intradiscal injection work in humans? Does it apply to all stages of degenerated discs or only for the early stage of degeneration? Clinically, how long would you expect to restore disc height? Which would be a difficult task, especially for the moderate to severe ones.

Authors: The phase $1 \mathrm{~b}$ study has been conducted using a single intradiscal injection of NF- $\kappa$ B decoy. The detailed clinical protocol is on ClinicalTrial.Gov and we refrain from a detailed discussion because this is beyond the scope of the present study. According to the trial protocol, one of the included criteria is a Pfirrmann score of 3 or 4 on MRI in just a single disc 
between L1 and S1. This means that degenerated discs should not be at the most severe stage of degeneration. The reference to the media release from the sponsor of the clinical study was included. As presented, a single injection of NF- $\kappa$ B decoy improved low-back pain with a considered minimal disc height maintenance/recovery at the 1-year time point. As the Reviewer indicated, the disc height recovery in the disc height of severely degenerated disc may be difficult to obtain, a further clinical trial for pain relief may be warranted.
Li Jin: How does the decoy oligodeoxynucleotide interfere with other immune cells?

Authors: It could interfere through systematic circulation. However, injected NF- $\kappa B$ decoy was rapidly excreted through urine, the effect on other immune cells is considered as a minimum.

Editor's note: The Scientific Editor responsible for this paper was Sibylle Grad. 